\title{
Recent developments in carbon-based two-dimensional materials: synthesis and modification aspects for electrochemical sensors
}

\author{
Eva-Maria Kirchner ${ }^{1} \cdot$ Thomas Hirsch $^{1}$ (I) \\ Received: 18 May 2020 / Accepted: 24 June 2020 / Published online: 12 July 2020 \\ (C) The Author(s) 2020
}

\begin{abstract}
This review (162 references) focuses on two-dimensional carbon materials, which include graphene as well as its allotropes varying in size, number of layers, and defects, for their application in electrochemical sensors. Many preparation methods are known to yield two-dimensional carbon materials which are often simply addressed as graphene, but which show huge variations in their physical and chemical properties and therefore on their sensing performance. The first section briefly reviews the most promising as well as the latest achievements in graphene synthesis based on growth and delamination techniques, such as chemical vapor deposition, liquid phase exfoliation via sonication or mechanical forces, as well as oxidative procedures ranging from chemical to electrochemical exfoliation. Two-dimensional carbon materials are highly attractive to be integrated in a wide field of sensing applications. Here, graphene is examined as recognition layer in electrochemical sensors like field-effect transistors, chemiresistors, impedance-based devices as well as voltammetric and amperometric sensors. The sensor performance is evaluated from the material's perspective of view and revealed the impact of structure and defects of the 2D carbon materials in different transducing technologies. It is concluded that the performance of $2 \mathrm{D}$ carbon-based sensors is strongly related to the preparation method in combination with the electrical transduction technique. Future perspectives address challenges to transfer 2D carbon-based sensors from the lab to the market.
\end{abstract}

Keywords Graphene $\cdot$ Reduced graphene oxide $\cdot$ Carbon nanomaterial $\cdot$ Exfoliation $\cdot$ Electrochemical sensor

\section{Introduction}

Ten years ago, J. Justin Gooding and Filip Braet have asked, "Should you use nanotubes or graphene as carbon nanomaterial in biosensors?" [1], motivated by numerous publications on carbon nanotubes in biosensing and the start of the graphene hype, which was discovered as a single flake about 15 years ago [2]. One decade ago, only a few papers using 2D carbon materials have been published and research on this topic was in the early stage where all those interesting properties coming with this material have been described; some of them even outperforming the ones known for carbon nanotubes (CNTs). Today, carbon-based nanomaterials have become one of the dominating materials in many sensor

Thomas Hirsch

thomas.hirsch@ur.de

1 Institute of Analytical Chemistry, Chemo- and Biosensors, University of Regensburg, 93040 Regensburg Germany applications. A web-of-science survey revealed up to now more than 2.200 publications related to nanomaterial and sensing and roughly about $50 \%$ of them deal with carbon nanomaterials. On a closer look, about half of the carbon materials are from the so-called graphene family. These impressive numbers raise the question why $2 \mathrm{D}$ carbon nanomaterials got so popular in sensing that one finds almost three times more publications with this class of materials compared to CNTs. Graphene, ideally consisting of a honeycomb structured monolayer of $\mathrm{sp}^{2}$-hybridized carbon atoms, is characterized as an almost transparent, chemically inert material, exhibiting high carrier mobility, as well as excellent electric and thermal conductivity [3, 4]. These properties are often mentioned together with a high surface-to-volume ratio as motivation why 2D carbon nanomaterials are used in (bio)analytical applications, especially for sensor development where also costs of materials come into play. In electroanalytical applications, carbon-based electrodes outperform many other materials, such as noble metals, because they are less prone to surface fouling and they are known for a wider 
electrochemical potential window ranging from -1.5 to $+1 \mathrm{~V}$ vs. $\mathrm{Ag} / \mathrm{AgCl}[5-8]$.

For sensor development, it is desired that the electrode fabrication can be performed in an easy way, allowing mass production, which is not in coincidence with the preparation of individual graphene flakes from graphite by the famous scotch tape method [2]. Many other manufacturing methods have been developed, and it turned out by sophisticated material characterization processes that those two-dimensional carbon materials are somehow similar to graphene, even when they contain many defects compared to an ideal graphene flake [2]. In the last years, the number of exfoliation protocols to obtain 2D carbon materials has risen, mostly motivated by the goal to produce a material, which comes as close as possible to a perfect graphene but to be accessible in large scale. It became clear, as for every nanomaterial, that intrinsic material properties with regard to the exfoliation process are differing a lot due to their flake morphology, which are varying in the size of the flakes, the amount of defects, the number of layers (mono-, bi-, few-, multi-layers), and the doping ratios [9, 10]. All the structural and chemical variations introduced during the processing of such materials change the intrinsic material properties. This leads to the question of how different exfoliation methods affect the properties of electrochemical sensors based on 2D carbon nanostructures, which is evaluated in this review.

\section{Synthesis and functionalization}

Preparation techniques for 2D materials are often classified either bottom-up or top-down approaches which are capable to create nanomaterials with a varying distribution of lattice defects. These include vacancies, grain boundaries, oxygen functional groups, dangling bonds, and Stone-Wales defects resulting in a certain degree of functionalization. Excellent reviews are published on the high diversity of preparation methods to yield two-dimensional materials [10-14]. With regard to the preparation method, the intrinsic characteristics of $2 \mathrm{D}$ materials can be chosen, as well as parameters such as the potential for scale-up-synthesis and processability, which influence their use as sensor material [10, 13, 15-17]. In the following, the most important fabrication techniques and functionalization strategies are critically evaluated.

\section{Chemical exfoliation}

The chemical synthesis is the widest distributed technique to obtain graphene, ensured by the simple instrumentation and the advantage to obtain aqueous dispersions of 2D carbon nanomaterials. Graphene oxide (GO) is synthesized by treating graphite with a strong acid and an oxidizing species, which delaminates the graphite crystal structure introducing oxygen functional groups. This material can be reduced in many ways to reduced graphene oxide (rGO), which is widely applied as sensor layer. Brodie paved the way for the graphene oxide synthesis already in 1859 by oxidizing graphite with potassium chlorate and fuming nitric acid [18], followed by Staudenmayer around 40 years later who modified Brodie's synthetic route slightly by stepwise oxidation of the graphite in a mixture of sulfuric acid and nitric acid. Potassium chlorate was added in small portions to avoid explosive reactions in a more acidic environment [19]. In 1957 Hummers and Offeman established a safer production method for GO. Graphite was oxidized by the addition of $\mathrm{KMnO}_{4}$ and $\mathrm{NaNO}_{3}$ in concentrated sulfuric acid [20]. This synthetic route is still applied nowadays by slight modifications with additional amounts of oxidizing agents for an increased oxidation rate of the material $[21,22]$. The high degree of oxygencontaining functional groups distributed along the surface of the GO flake leads to an electrically insulating material. The interlayer spacing of the sheets is increased by the oxidation of graphite with oxidizing agents forming epoxy, hydroxy, and carboxyl groups [23]. Oxidative cleavage cause in-plane voids and cracks at the edges [24]. The subsequent reduction of GO eliminates the oxygen residues, restoring the $\mathrm{sp}^{2}$-hybridized carbon system and its conductivity. Figure 1 indicates that the reduction step cannot remove structural defects of the material, which originate from the oxidation process [24]. Reduced
Fig. 1 Chemical structure of highly defective graphene oxide. The reduction process leads to a restored $\mathrm{sp}^{2}$-hybridized carbon lattice with oxygen moieties at the edges of the flakes. The elimination of structural defects within the material is not feasible

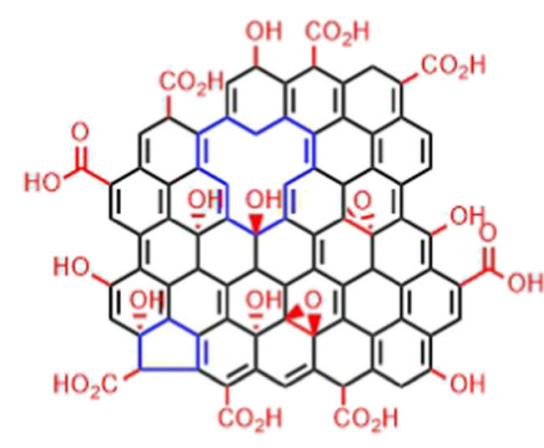

Graphene oxide

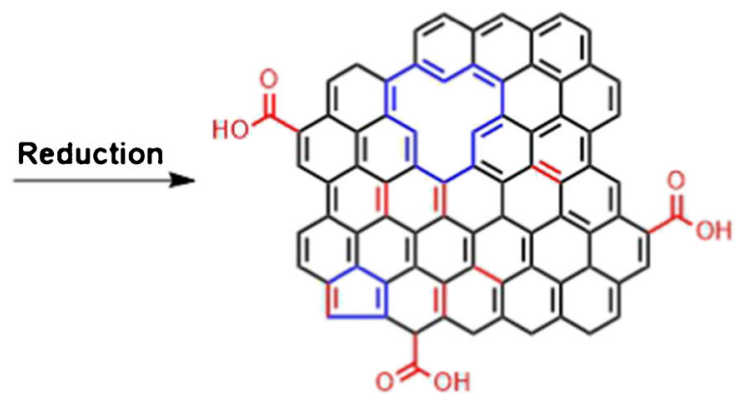

Reduced graphene oxide 
graphene oxide is classified as highly defective material. The harsh oxidation and subsequent reduction process introduce structural defects as well as oxygen moieties [25].

The thermal treatment is the simplest way to reduce GO [26-28]. Many of the thermal reduction steps to form rGO are performed hydrothermally in an autoclave to reduce the precursor material under high temperature and pressure $[22,29$, 30]. A chemical reduction, mainly by hydrazine, ascorbic acid, sodium citrate, hydroiodic acid, or sodium borohydrate is also quite common [29, 31-33].

An advantage of the aqueous dispersed $\mathrm{rGO}$ compound is the facile transfer mechanism for chemically synthesized 2D materials $[13,30,34-36]$. Spin-casting requires an inkformulation to ensure a fast evaporation of the solvent as well as the application of ideal processing parameters in order to form a coherent, homogeneous film [37]. Drop coating from aqueous dispersion seems easier but is challenging in resulting homogeneous films.

Chemical synthesis of 2D materials provides a large degree of freedom to adjust process parameters. So far, these options have not been fully exploited, e.g., by the design of 2D materials with a controlled number of defects. Such materials might be of great interest in sensing applications. It is observed for surface functionalization by nanoparticle (NP) deposition that the structural irregularities act as nucleation sites for the particles [35]. Defects allow the introduction of bandgaps, which might be beneficial in field effect transistors [38].

In comparison to chemical synthesis, which needs, in total, several days to proceed, the exfoliation can be speeded up to hours by applying a strong electrical potential to graphite electrodes. Upon application of an electrical voltage, solvated ions of the electrolyte intercalate within the graphite working electrode, weakening the interlayer forces and driving the individual flakes apart, which are released into the electrolyte $[39,40]$. The application of a negative potential to the graphite electrode in organic medium force positively charged ions between the layers of the bulk material, which is called cathodic electrochemical exfoliation. The applied voltage, size of the anions, and the type of solvent do not only affect the intercalation process but also have an impact on the quality of processed material. The cathodic electrochemical exfoliation is either carried out by intercalating $\mathrm{Li}^{+}$ions or quaternary ammonium salts in organic solvents [41-43]. Anodic exfoliation is performed in aqueous solution, where anions intercalate between the graphite layers upon electrolysis, triggering the delamination (Fig. 2). Parvez et al. extensively studied the exfoliation efficiency of various inorganic salts $\left(\mathrm{NH}_{4} \mathrm{Cl}\right.$, $\mathrm{Na}_{2} \mathrm{SO}_{4},\left(\mathrm{NH}_{4}\right)_{2} \mathrm{SO}_{4}, \mathrm{NaNO}_{3}, \mathrm{~K}_{2} \mathrm{SO}_{4}$, and $\left.\mathrm{NaClO}_{4}\right)$. Sulfate yields large graphene flakes with a lateral size up to $44 \mu \mathrm{m}$ (>85\% with $\leq 3$ layers) and no exfoliation was observed for $\mathrm{ClO}_{4}{ }^{-}, \mathrm{Cl}^{-}$, and $\mathrm{NO}_{3}{ }^{-}$[44].

Raman spectroscopy, a versatile tool for non-destructive optical characterization of 2D materials, revealed that the material got oxidized during the exfoliation procedure exhibiting major structural defects [45]. The electrochemical exfoliation procedure is not that widely integrated into sensor preparation so far. A reason might be that this method was only recently developed. Several advantages such as less labor-intense, easier control of flake size, and defects by the ideal choice of intercalating salts and electrochemical potentials let one expect that electrochemical exfoliation might become more attractive in the future.
Fig. 2 Scheme of an anodic electrochemical exfoliation process of graphite. Oxidation of water causes the formation of oxygen-containing species attacking the edges and grain boundaries of graphite promoting the $\mathrm{SO}_{4}{ }^{2-}$ intercalation and exfoliation of graphene layers. Reprinted with permission from [44]. Copyright 2014 American Chemical Society
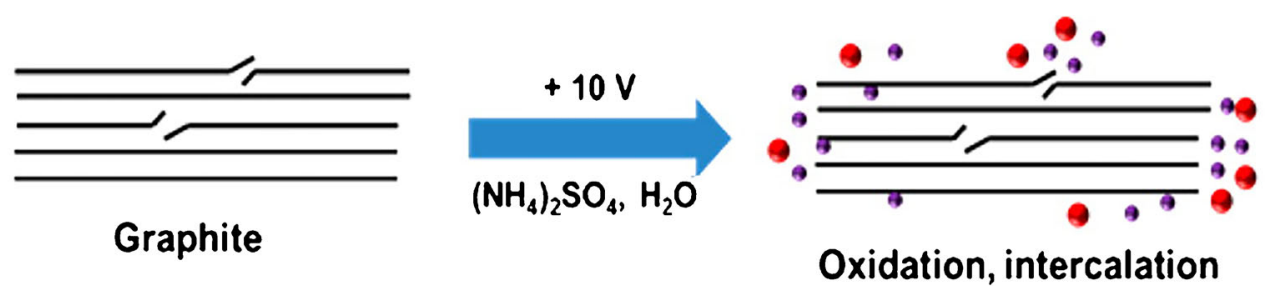

- $\mathrm{H}_{2} \mathrm{O} \bullet \mathrm{SO}_{4}{ }^{2} \cdot \Theta \mathrm{O}_{2} \Theta \mathrm{CO} \Theta \mathrm{SO}_{2}$

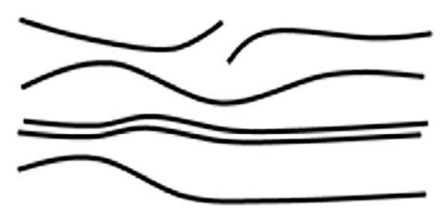

Exfoliated graphene
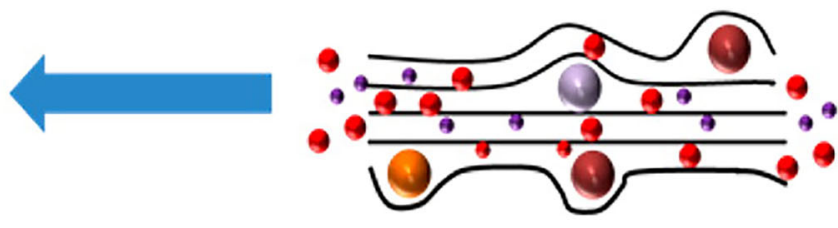

Expansion of graphite layers 


\section{Chemical vapor deposition}

Chemical vapor deposition (CVD) gained its popularity due to the possibility to grow large high-quality 2D carbon materials [46]. The growth mechanism of this bottom-up technique depends on the metallic catalyst triggering the layer deposition. There are two prominent representatives of catalytic support, $\mathrm{Ni}$ and $\mathrm{Cu}$, which differ in the deposition mechanism as highlighted in Fig. 3. Generally, the growth of graphene on $\mathrm{Ni}$ is hardly controllable. The high solubility of $\mathrm{C}$ atoms in $\mathrm{Ni}$ can lead to the formation of CVD graphene (cvdG) domains with different thickness resulting in an inhomogeneous layer. In contrast to $\mathrm{Ni}$, the growth on $\mathrm{Cu}$ bases on a self-limiting surface adsorption process, attributed to the low solubility of $\mathrm{C}$ atoms in $\mathrm{Cu}$ [47-49]. The decomposed carbon atom nucleates on top of the metallic surface forming ordered crystals subsequently growing a two-dimensional carbon layer [39, $49,50]$. The issue of multi-layered cvdG grown on Ni seemed to be solved by cvdG on $\mathrm{Cu}$ substrates on the price of grain boundaries and wrinkles along its surface [49-51], which might affect the physical properties of the material and therefore the sensing performance.

Apart from the deposition, the layer transfer to a substrate of choice is still challenging for $2 \mathrm{D}$ carbon materials prepared by CVD. Etching of the metallic substrate increases the cost and introduces ionic impurities [49, 53]. A postintroduction of defects can be caused by electrochemical or mechanical delamination [54]. The films are prone to the introduction of cracks and wrinkles, which lead to a deterioration of the physical properties [55]. In contrast, a systematic introduction of defects by transferring cvdG, specifically to form a wrinkled layer, was found to induce a bandgap [56]. Besides the transfer, also a modification might induce defects within the CVD grown layer. To establish an $\mathrm{NO}_{2}$ senor, a pulsed laser deposition of $\mathrm{ZrO}_{2} \mathrm{NPs}$ or AgNPs on cvdG did not only decorate the carbon layer but also introduce defects [57].

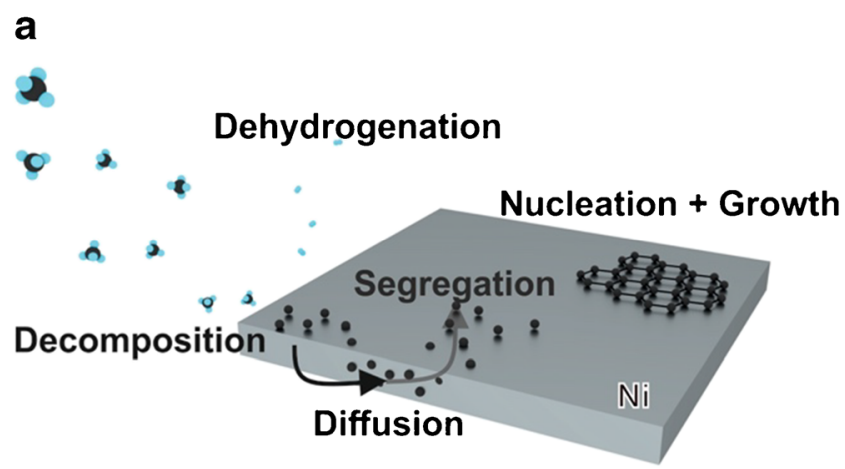

Fig. 3 Schematic illustration of the cvdG growth process on a carbonsoluble metal support (Ni) where the hydrocarbon molecules, e.g., methane, decompose and the $\mathrm{C}$ atoms diffuse into the bulk of the metal. The $\mathrm{C}$ atoms segregate upon supersaturation, nucleate, and grow a carbon layer
Even though, research aims for ongoing improvement of the growth mechanism to achieve large-area films of highqualitative graphene material, mostly for optoelectronic applications such as displays, it became apparent that there is no need for the growth of large films in sensing applications, since most electrochemical sensors operate with small electrodes in the $\mathrm{mm}^{2}$ range or even smaller. Moreover, the preparation method still is time-consuming and compensates a lot of energy due to the high operating temperature of around $1000^{\circ} \mathrm{C}$. To circumvent the need of a metallic catalyst requiring a subsequent transfer step as well as to reduce the deposition temperature, the growth of graphene on non-conductive materials, such as $\mathrm{SiO}_{2}$, was developed [58]. Figure 4 schemes the growth procedure, which does not result in a horizontal growth of the carbon material, but deposits vertically oriented graphene flakes, which additionally enhances the surface area of the carbon layer. In terms of larger surface-to-volume ratio, such vertically aligned carbon 2D materials should outperform horizontally aligned carbon layers in sensor applications which rely on a large specific surface area.

\section{Liquid phase exfoliation}

An alternative synthesis routine was investigated to obtain high qualitative 2D materials dispersed in liquid medium. This method can be applied to numerous bulk crystals, yielding colloidal stable dispersions (Fig. 5), which are supposed to facilitate the processability of the material and a scale-up in liter-sized batches is possible.

In contrast to chemical synthesis, either by oxidizing graphite under harsh conditions yielding $\mathrm{GO}$, the liquid phase exfoliation (LPE) takes advantage of a direct, mild exfoliation of the bulk material in liquid medium $[60,61]$. It yields materials free of defects within the basal plane. This method is solely based on the application of ultrasound or shear forces and does not need further sophisticated equipment. Liquid

b

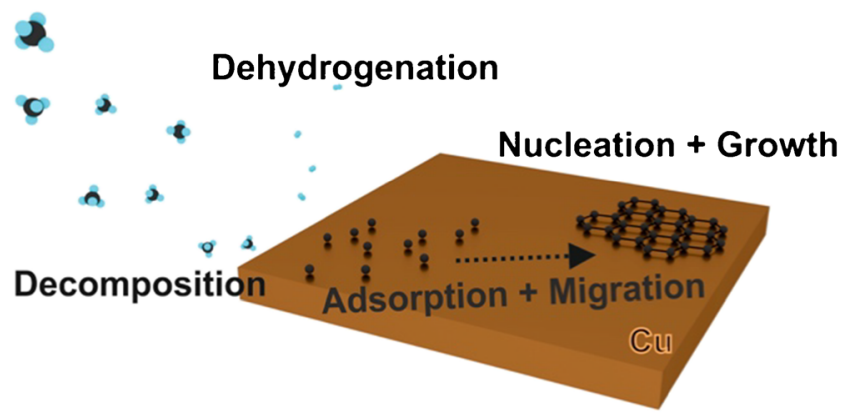

(a). On a $\mathrm{Cu}$ substrate, the hydrocarbons decompose as carbon poorly segregates in copper. The adsorbed adatoms migrate along the surface, nucleate, and form the graphene layer (b). As depicted in detail by Muñoz and Gómez-Aleixandre [52] 
Fig. 4 Illustration of the preparation process of graphene derived by plasma-assisted CVD growth (a). The numbers (I-IV) scheme the corresponding SEM images $(\mathbf{b}-\mathbf{g})$. The $\mathrm{SiO}_{2} / \mathrm{Si}$ support (I, b) was modified by depositing a carbon buffer layer (II, c), followed by the introduction of defects within the material (III, d) forming nanoislands (IV, e). At the edges of the nanoislands, the growth of graphene is initiated $(\mathrm{V}, \mathrm{f})$, resulting in the vertical growth of graphene flakes (VI, g). Reprinted from [58] with permission from The Royal Society of Chemistry
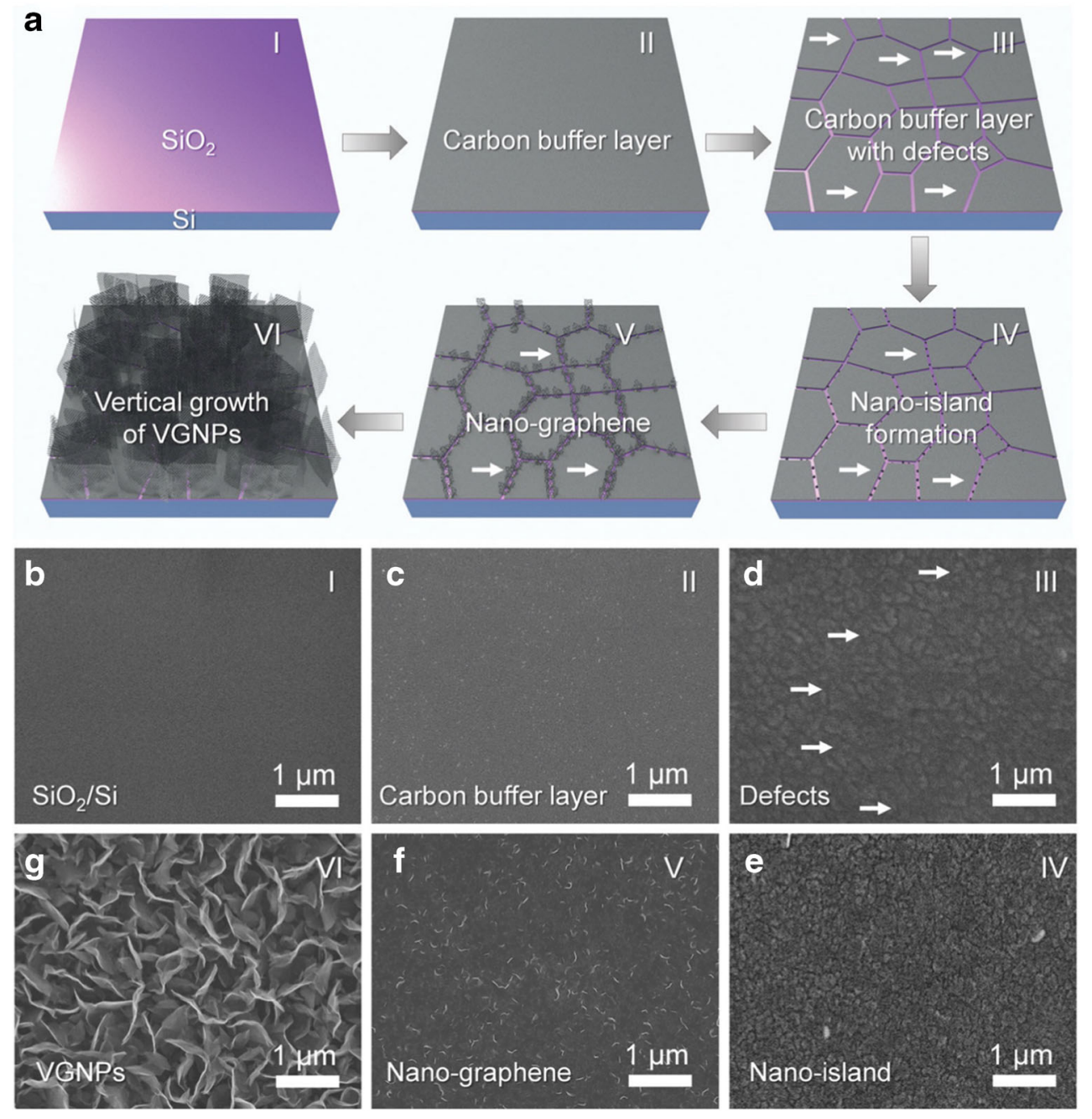

phase exfoliation imposes three steps. First, the weak interlayer van der Waals forces must be overcome by introducing energy during the exfoliation procedure. Second, the exfoliated nanosheets have to be stabilized against reaggregation by choosing an appropriate solvent or surfactant. Third, the purification and size selection of the obtained batch of exfoliated layered material. The last step is necessary to get rid of unexfoliated material as well as to distinguish fractions with a certain size and number of layers [62].

Coleman et al. pioneered the field of LPE [63]. The exfoliation bases on sonication, which induce the formation of cavitation, generates micro jets and shock waves (Fig. 6). The resulting tensile stress and shear stress cause the delamination and fragmentation of the bulk material $[12,64,65]$. It is reported that the material preparation based on shear forces induced by rotating blade mixers is more applicable in industrial-scale production compared to ultrasound [66]. The exfoliation time for sonication requires a few hours, whereas shear exfoliation consumes more time to yield the same amount of 2D material. Nevertheless, larger volumes in liter range can be produced by shear exfoliation contrary to ultrasound, which yields fractions of less than 0.5 L. [62]
Fig. 5 Variety of liquid-phase exfoliated 2D materials dispersed in appropriate solvent. Reprinted with permission from [59]. Copyright 2015 American Chemical Society

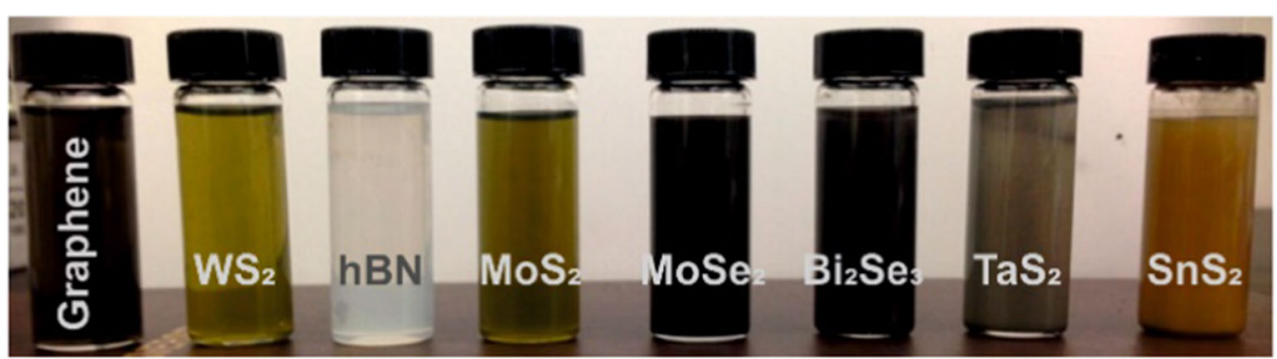



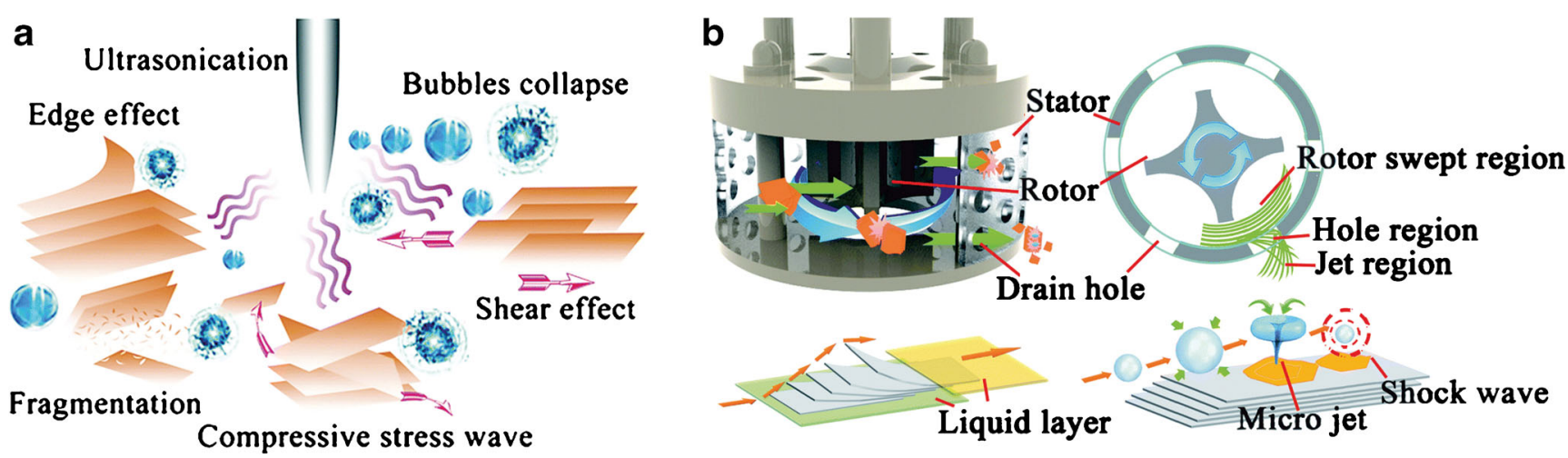

Fig. 6 Scheme of liquid phase exfoliation strategies based on ultrasound (a) [64] or shear forces (b) [65]. Reproduced from [64] with permission from the PCCP Owner Societies. Adapted from [65] with permission from The Royal Society of Chemistry

The choice of the solvent is the key in terms of production. Apart from the effective delamination of the material, it is mandatory to keep the dispersion colloidal stable. This can be achieved when the solvent and delaminated material match in surface energies and possess similar Hansen solubility parameters $[67,68]$. High boiling point solvents like $N, N$ dimethylformamide (DMF) and $N$-methyl-1-pyrrolidone (NMP) were found to be versatile dispersants [69-71]. One might assume that the simple LPE exfoliation is an excellent method to produce almost defect-free $2 \mathrm{D}$ materials without any additional impurities, but this comes for the price of delaminated flakes with inhomogeneous morphology. A reproducible preparation of defined mono- to multi-layered flakes with varying flake size is challenging.

Liquid-phase exfoliation is gaining more interest due to the timesaving, up-scalable exfoliation, which yield materials mostly unchanged in their chemical structure ranging from dispersed monolayers to few-layers [72]. So far, only a very limited number of sensor application make use of 2D materials prepared by LPE. One reason might be that the solvents which warrant colloidal stability are hardly removed by washing steps or thermal treatment [73], which may cause a deterioration of electronics and sensing devices.

In contrast to many noble metal, 2D carbon materials have been reported as stable against electrode fouling. This was demonstrated by copper electrodes which were partly covered by cvdG. Even for inner sphere redox couples, no apparent fouling was observed [74].

\section{Functionalization}

The high surface-to-volume ratio and large $\mathrm{sp}^{2}$-hybridized carbon system are key properties of 2D carbon materials to be integrated into a sensor device. Analyte interaction can take place via $\pi$-interaction of the extended aromatic carbon system or by hydrogen bonding with the oxygen residues present within and at the edge-planes of the graphene flakes. The introduction of additional recognition elements is highly desired to enhance the sensitivity and selectivity of the carbon material. Georgakilas et al. published detailed reviews on the functionalization of graphene, covalently and non-covalently $[75,76]$. Therefore, the most common modification routines are only briefly introduced, with emphasis on their use in electrochemical sensors. Non-covalent modifications take place via $\pi$-stacking, van der Waals forces, ionic interactions as well as due to hydrogen bonds [76]. These functionalization strategies are less selective, but the $\mathrm{sp}^{2}$-hybridized carbon lattice remains intact. Intermolecular interactions with materials exhibiting a $\pi$ system are feasible [75, 77-79]. Especially porphyrins are promising, as they exhibit a metallic core, which can mimic enzymatic-like reactions or induce a change in the physical properties of graphene resulting in an opened bandgap, potentially tuning its intrinsic characteristics [80, 81]. One has to be cautious as there is no bandgap control upon non-covalent functionalization, which might be used in maximizing the detection sensitivity by minimizing the electrical noise [76]. Pyrene derivatives have been reported as non-covalent linker between graphene and other (bio-)molecules, which act either as probe or as target [32, 82, 83]. The $\pi$-interaction of graphene with carbon nanotubes enables the processability of the former hydrophobic carbon wires in aqueous solution [84]. The carbon surface is decorated by deposition of metallic nanoparticles, i.e., noble metals. Preferably, defective graphene materials are used as support, as it provides numerous nucleation sites for the deposition of the metallic nucleus growing to a particle [30, 35, 84-87]. Covalent modifications were initiated by anodization of graphene layers to introduce more oxygen functionalities or by a radical reaction, forming a diazonium salt that attacks the $\mathrm{sp}^{2}$-hybridized carbon lattice [71, 88]. Oxygen functionalities present at the surface of defective graphene compounds offer binding sites for linkage via carbodiimide coupling [77]. The covalent attempt is often found for biomolecular modified graphene compounds, as the amide bonds combine with the oxygen residues of graphene. Ultra-high pressures allow to 
tune the doping ratio of graphene surfaces [89]. The reactivity towards oxygen was shown to be enhanced by charge-doping under photothermal heating applying either positive or negative pulsed back gate voltages causing either electron doping or hole doping. Back gating without photothermal treatment did not result in a doping effect. The charge-doped-increased reactivity poses as an alternative to chemical-based catalysis, which can potentially enhance and control the chemical reactivity of a material [90]. A non-destructive functionalization technique is the creation of stacked van der Waals heterostructures. Structural relatives of two-dimensional graphene, e.g., transition metal dichalcogenides or hexagonal boron nitride, act as building blocks to tremendous possibilities of material design tuning the physical properties of the materialistic compounds [91, 92].

\section{Sensors}

The direct interaction of graphene-like materials with analytes or ease of functionalization as well as the tenability to obtain materials either of metallic, semiconducting, or insulating character is highly attractive for electrochemical sensors. Excellent reviews focus on the sensing capabilities of 2D carbon materials towards numerous analytes [93-97]. A critical evaluation of the effect and requirements for 2D carbon materials in different types of electrochemical sensors is missing so far and presented in the following.

\section{Field-effect transistors and chemiresistors}

In field-effect transistors (FET), semiconducting 2D carbon materials act as channel between source and drain electrode applying a potential of the gate electrode. Two sensing types are accomplished, either back-gating or top-gating, also known as solution-gating. The interaction of the analyte with the 2D carbon material changes its charge carrier density due to electric charge distribution making this technology capable to develop rapid, miniaturized sensors [98]. A chemiresistor is similar to the FET. The detection principle remains the same, but it omits the gate electrode. The slightly more complex electronics of FETs compared to chemiresistors enable better sensitivity by tuning the conductance of the material by controlling the gate voltage. Both techniques can easily be adapted for commercialization. 2D carbon nanomaterials are preferably used due to excellent chemical stability and electric field sensitivity (Fig. 7) [98].

In a graphene FET (GFET), the material is accessible to surface functionalization as the channel is partially integrated into the device and the electrical double layer allows operation at low gate voltage with high conductivity. Monolayer graphene may be superior compared to multi-layered graphene as the conductance is improved. This is demonstrated by a DNA sensor, where the probe DNA was coupled to monolayer graphene via a pyrene butyric $\mathrm{N}$ hydroxysuccinimide ester showing an outstanding limit of detection (LOD) of $25 \mathrm{aM}$ for 24 mer target DNA [82]. A FET targeting at DNA, based on multi-layer graphene, was found to detect a 42 mer target DNA down to $10 \mathrm{fM}$. Here, graphene exfoliated by ultrasonication in DMF was used as channel material. The fabrication of the transistor is rather complicated. The substrate needs to be modified by glutaraldehyde and LPE graphene was drop-coated on top of the surface. The formation of a continuous film of carbon 2D material required a two times repetition [99]. To enhance the surface area, rGO was drop-casted onto a substrate to be used as channel material, providing a rough carbon layer. A peptide nucleic acid (PNA)-DNA hybridization FET was accomplished, by attaching the PNA by $\pi$-interaction of a pyrenelinker to the rGO. At constant bias voltage $\left(V_{d s}=0.1 \mathrm{~V}\right)$ the highly selective sensor showed a LOD of $100 \mathrm{fM}$ for a 22-mer DNA strand [32]. These three examples in DNA sensing based on FET transduction show that a lower number of

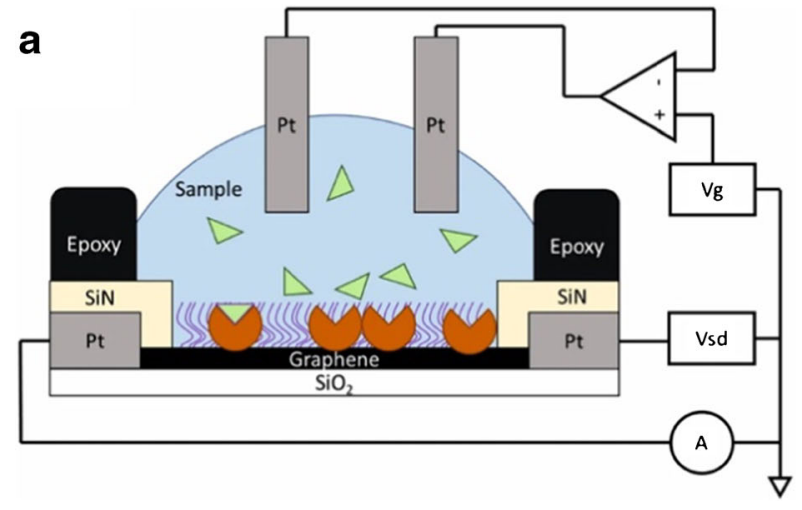

Fig. 7 Scheme of a graphene field effect transistor with symbolized proteins linked to the 2D carbon material (a). The entire sensor surface of a commercial sensor showing five sensing spots with a red scale bar of
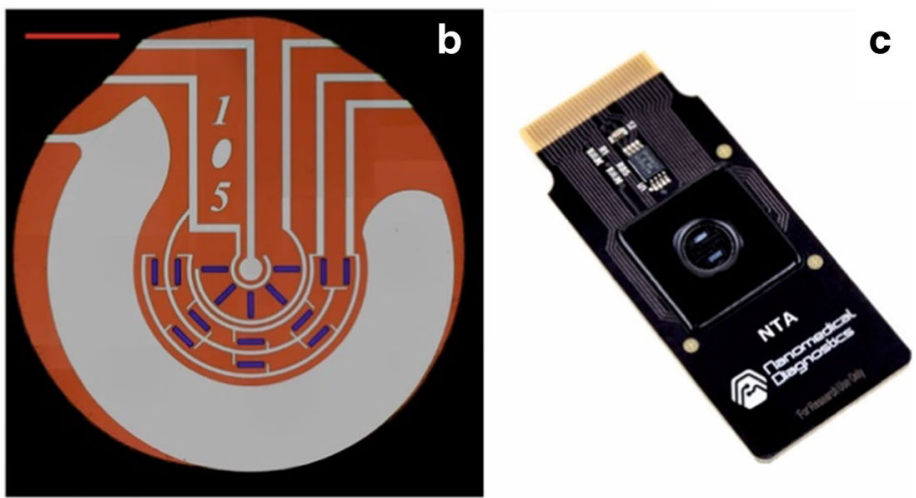

$1 \mathrm{~mm}$ is depicted in (b). A photograph of the fully integrated graphenebased senor chip from Nanomedical Diagnostics is shown in (c). Adapted from [98]. Copyright (2019) Springer Nature 
defects and a lower number of layers achieve slightly better detection limits. The superior conductivity of the material outperforms the enlarged surface area by improved signal-tonoise ratios.

On the other hand, defects are reported to enhance the sensitivity. This was demonstrated for a glucose sensor by fabricating a graphene mesh via CVD on a copper foil where certain areas were blocked by silica spheres [100]. The edge defects can be used to link the enzyme glucose oxidase (GOx) to the carbon material improving the charge transfer. Compared to the same sensor with cvdG, the sensitivity was enhanced from -0.37 to $-0.53 \mathrm{mV} \mathrm{mM}^{-1}$ for the graphene mesh. A similar effect was reported, when it was discovered that certain graphene-based $\mathrm{pH}$ sensors can exceed the theoretical maximum Nernst limit of $59 \mathrm{mV} \mathrm{pH}^{-1}$ in sensitivity. This was also attributed to defects, which allow in addition to the electrostatic gating effect a direct transfer of the charge carriers to the 2D carbon material [101].

Disease-related small marker molecules like glucose [100], dopamine [87], urea [102], or environmental-related parameters such as $17 \beta$-estradiol [103], $\mathrm{pH}$ [104], heavy metal ions [105], or chlorine [106] have also be determined by GFETs. Selectivity can be achieved by using a differential measurement of two differently modified GFETs as it is illustrated in Fig. 8. This can easily be realized without complicating the fabrication process and due to the miniaturized size of GFETs, this does not affect the total size, the sample consumption, or the need of any complex electronics.

In general, cvdG is the material of choice in terms of miniaturization and mass production. Even when mass production still suffers from defects, originating of polymer contamination, affecting $44.2 \%$ of all chips [98], this material is easier to handle compared to carbon nanotubes or solvent dispersed carbon 2D materials in small dimensions. Transferred monolayers can be further etched by using masks in combination with oxygen plasma.

One of the rare exceptions of using rGO in FETs was reported by the group of Wolfgang Knoll. They report on a layer-by-layer (LbL) assembly of urease and polyethyleneimine on $\mathrm{rGO}$ and exploit the $\mathrm{pH}$ dependency of liquid-gated GFETs when detecting urea [102]. The LbL technique was chosen to neither disrupt the functionality of the biomolecule [107] nor to damage the $\mathrm{sp}^{2}$-hybridization of the graphene lattice [108]. Reduced GO is advantageous for $\mathrm{pH}$ sensing due to its defective structure, which allows a change in the surface charge density and the electric double layer when $\mathrm{pH}$ is changing, causing additional electrostatic gating effects [109].

Graphene FETs have also been reported as a platform for immunosensors, e.g., to determine emerging pathogens such as coronavirus 2 (SARS-CoV-2) (Fig. 9). Graphene, as supporting layer, equips the FET with a highly conductive material providing a large surface area to enable low-noise detection of the virus. A SARS-CoV-2 spike antibody modified with a pyrene linker was assembled to cvdG by $\pi$-stacking. The sensor was highly sensitive for SARS-CoV-2 in clinical samples as well as selective compared to Middle East respiratory syndrome coronavirus (MERS-CoV). The detection limit is $1 \mathrm{fg} \mathrm{mL}^{-1}$ for the SARS-CoV-2 antigen protein. The sensor proved to be successfully applied in clinical diagnosis as nasopharyngeal swab specimen from COVID19 patients and healthy persons were investigated [110].

Chemiresistors are extremely popular in gas sensing. Here, 2D carbon materials can add additional value by their high affinity to gasses, together with excellent conductivity and catalytic effects. Figure 10 shows a measurement device with an array of chemiresistors recording the change of conductance in presence of $\mathrm{NH}_{3}$ gas under different environmental conditions, which is enhanced by the recognition elements, cobalt meso-arylporphyrins [111].

The high operating temperatures (often $>200{ }^{\circ} \mathrm{C}$ ) are one of the major drawbacks in gas sensing with semiconducting metal oxides, which can be overcome. Ammonia is one of the most frequently studied analytes, as it is harmful to humans already at very low concentrations. The threshold concentration is $25 \mathrm{ppm}$ for an exposure time of $8 \mathrm{~h}$ [112]. Besides
Fig. 8 Scheme of a combination of two aptamer-modified GFETs allowing via differential measurement to distinguish between analyte binding and non-specific binding (a). Microscopic image of the electrode layout (b). Reprinted with permission from [103]. Copyright (2019) Elsevier a

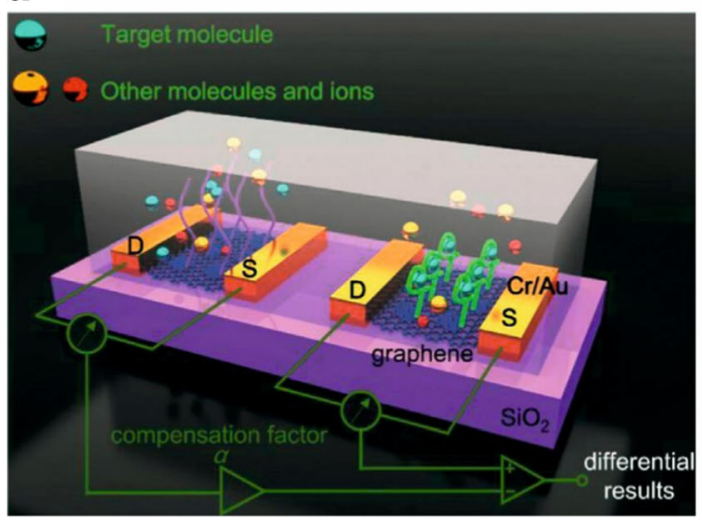

b

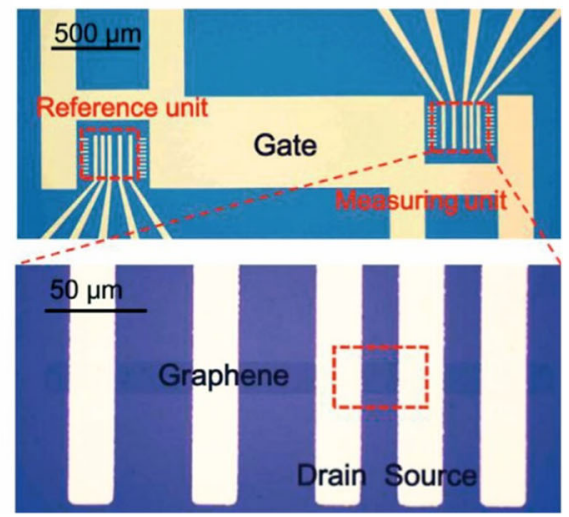




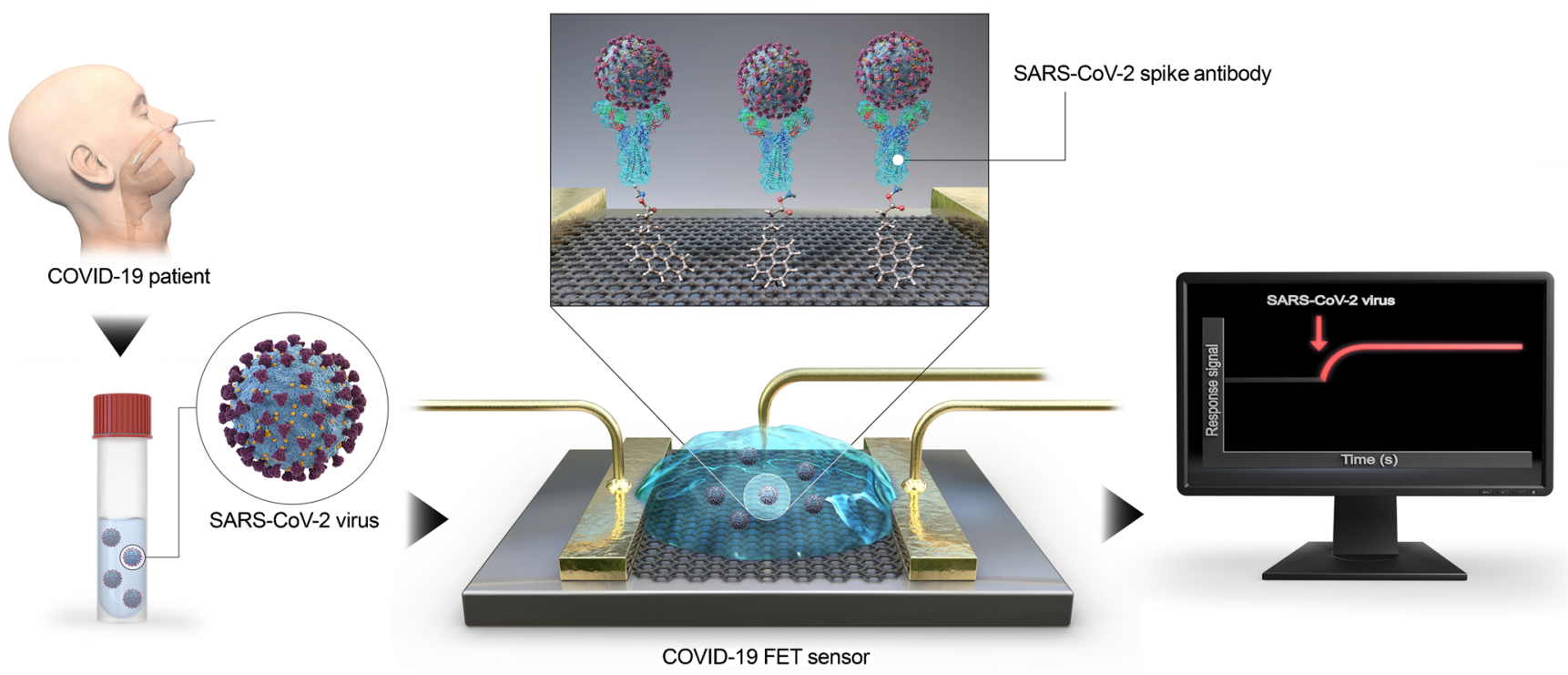

Fig. 9 Schematic operation procedure of the COVID-19 FET using graphene as channel material, modified by 1-pyrenebutyric acid $\mathrm{N}$ hydroxysuccinimide ester via $\pi$-stacking, coupling the SARS-CoV-2

safety issues, ammonia is also known as health marker in breath or to monitor food quality [113]. Graphene oxide reacts to ammonia with functional groups, accompanied by a decrease in its conductivity, which is usually attributed to pdoping of physically adsorbed oxygen. To introduce selectivity, several functionalization strategies have been studied. The most promising are phthalocyanines, especially with $\mathrm{Cu}$ as central metal, to be used in breath analysis [114]. A high selectivity was found for many volatile organic compounds (VOCs) and what is more, the combination of GO with $\mathrm{Cu}$ tetra- $\beta$-amine-phthalocyanines strongly reduces the crosssensitivity to humidity. Humidity is one of the major interfering substances when it comes to the quantification of gases at room temperature. For low relative humidity (r.h.) $(<30 \%)$, water adsorbs on the 2D material's surface and acts as an electron acceptor, which increases the electrical conductivity. When r.h. gets larger, the water molecules adsorbed on the spike antibody. Reprinted with permission from [110]. Copyright (2020) American Chemical Society

sensor surface can be ionized, $\mathrm{H}_{3} \mathrm{O}^{+}$is formed, which acts as charge carrier. In such cases, both electrical and ionic conductivity will be enhanced and the sensor is interfered. Therefore, the choice of the 2D carbon material has an impact on sensitivity as well as on selectivity. The complexity in the surface chemistry of 2D materials decreases in the order of $\mathrm{GO}<\mathrm{rGO}$ $<$ LPE graphene < cvdG. In the same order, the conductivity of the material increases. A large variety in surface chemistry might be attributed to many binding sites, either for adsorption of the gas itself or for easy modification with metal or metal oxide nanoparticles, which further increase the surface area, number of binding sites, binding affinities, or even may introduce electrocatalytic effects. Table 1 summarizes the recent achievement of ammonia sensors operated at room temperature in the order of the carbon materials used. A remarkable short response and recovery time of few seconds only was found when using rGO in combination with silver a

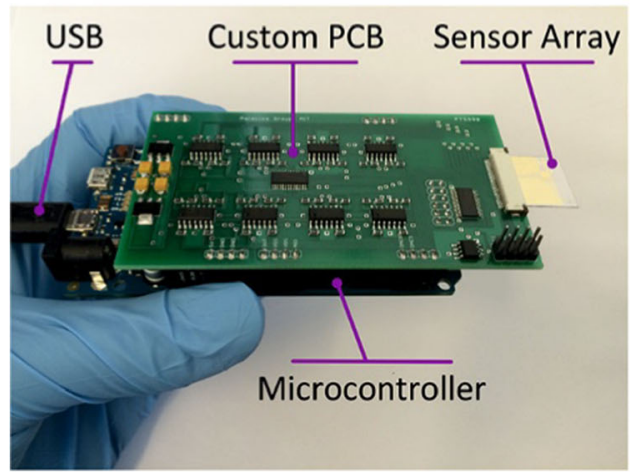

b

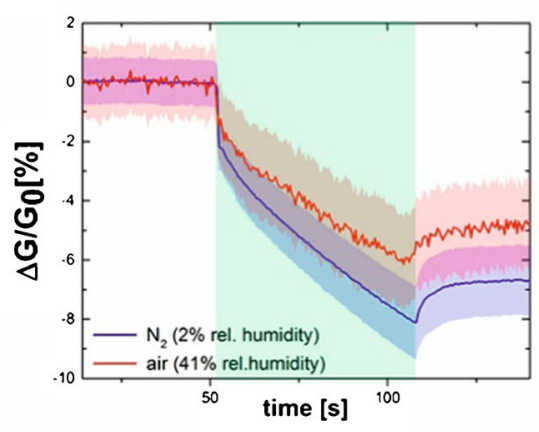

C

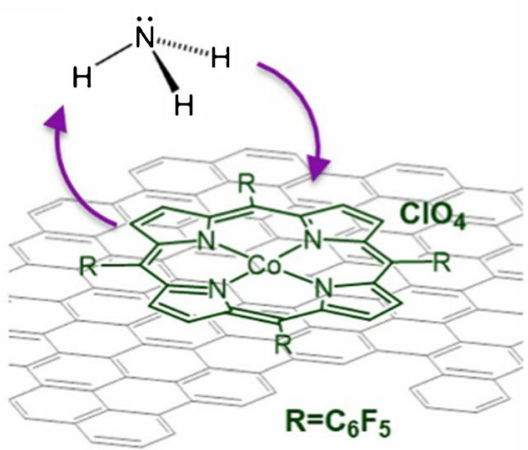

Fig. 10 A measurement device with implemented sensor array (a), recording the change of conductivity upon exposure to gaseous $\mathrm{NH}_{3}$ under varying environmental conditions (b). The sensitivity is enhanced by graphene functionalized with cobalt meso-arylporphyrins, which interact with the analyte (c). Reprinted with permission from [111]. Copyright (2018) American Chemical Society 
Table 1 Chemiresistive transducers based on differently fabricated 2D carbon materials for quantification and determination of ammonia at room temperature

\begin{tabular}{|c|c|c|c|c|c|c|c|c|}
\hline Material & Modification & LOD & $\begin{array}{l}\text { Range/ } \\
\text { ppm }\end{array}$ & $\begin{array}{l}\text { Response/ } \\
\text { recovery }\end{array}$ & $\begin{array}{l}\text { r.h./ } \\
\%\end{array}$ & Selectivity & Comment & Reference \\
\hline $\mathrm{cvdG}$ & - & - & $\begin{array}{r}(0.1-1) \\
10^{-4}\end{array}$ & $\begin{array}{r}4 \mathrm{~min} / \mathrm{few} \\
\min (-)\end{array}$ & - & - & $\begin{array}{l}\text { Vertically } \\
\quad \text { aligned cvdG }\end{array}$ & {$[58]$} \\
\hline cvdG & Co meso-arylporphyrins & - & $20-160$ & $60 \mathrm{~s} /-(-)$ & 41 & VOCs & FET & {$[111]$} \\
\hline cvdG & Ag NPs & - & $\begin{array}{l}(0.05-1.2) \\
10^{4}\end{array}$ & $120 \mathrm{~s} / 70 \mathrm{~s}(-)$ & 30 & VOCs & - & {$[117]$} \\
\hline ecG & $\mathrm{ZnO}$ nanowires & - & $0.5-50$ & $\begin{array}{l}6 \mathrm{~s} / 36 \mathrm{~s} \\
(0.5 \mathrm{ppm})\end{array}$ & - & $\begin{array}{l}\text { VOCs, benzene, nitrobenzene, } \\
\text { nitrotoluene }\end{array}$ & - & [118] \\
\hline rGO & Ag NPs & $1.2 \mathrm{ppb}$ & $0.1-15$ & $\begin{array}{l}5 \mathrm{~s} / 6 \mathrm{~s} \\
\quad(0.1 \mathrm{ppm})\end{array}$ & 25 & $\mathrm{H}_{2}, \mathrm{CO}$ & - & [115] \\
\hline rGO & $\mathrm{In}_{2} \mathrm{O}_{3}$ nanofibers & $44 \mathrm{ppb}$ & $1-60$ & $17 \mathrm{~s} / 214 \mathrm{~s}(-)$ & 30 & $\begin{array}{l}\text { Organic solvents, nitrogenated } \\
\text { compounds }\end{array}$ & $\begin{array}{l}\text { Impedance at } \\
10 \mathrm{kHz}\end{array}$ & [119] \\
\hline rGO & Mesoporous PPy layer & $200 \mathrm{ppb}$ & $10-40$ & $5 \mathrm{~min} / 10 \mathrm{~min}$ & - & $\begin{array}{l}\text { VOCs, acetonitrile, } \\
\text { chlorobenzene, EA, toluene }\end{array}$ & $\begin{array}{l}\text { No influence on } \\
\text { humidity }\end{array}$ & {$[120]$} \\
\hline rGO & MXene & - & $10-50$ & - & - & $\begin{array}{l}\text { VOCs, } \mathrm{H}_{2} \mathrm{~S}, \mathrm{SO}_{2} \text {, xylene, } \\
\text { benzene }\end{array}$ & - & {$[121]$} \\
\hline rGO & $\mathrm{SnO}_{2}$ nanorods & $20 \mathrm{ppm}$ & $20-3000$ & $\begin{array}{l}8 \mathrm{~s} / 13 \mathrm{~s} \\
\quad(200 \mathrm{ppm})\end{array}$ & 45 & VOCs, $\mathrm{NO}, \mathrm{CO}, \mathrm{H}_{2} \mathrm{~S}$ & $\begin{array}{l}\text { No influence on } \\
\text { humidity }\end{array}$ & [116] \\
\hline GO & Fluorinated & $6 \mathrm{ppb}$ & $0.1-0.5$ & $86 \mathrm{~s} / 116 \mathrm{~s}(-)$ & - & VOCs, $\mathrm{NO}_{2}, \mathrm{H}_{2}$, toluene & - & {$[122]$} \\
\hline GO & $\begin{array}{l}\mathrm{Cu} \\
\text { tetra- } \beta \text {-amine-phthalocya- } \\
\text { nine }\end{array}$ & - & 0.8 & $-/ 350 \mathrm{~s}(-)$ & - & VOCs, $\mathrm{NO}_{2}$ & $\begin{array}{l}\text { No influence on } \\
\text { humidity }\end{array}$ & [114] \\
\hline
\end{tabular}

$P P y$ polypyrrole, $E A$ ethyl acetate

nanoparticles [115] or $\mathrm{SnO}_{2}$ nanorods [116]. This might be ascribed to the catalytic effects of $\mathrm{Ag}_{2} \mathrm{O}$ and the $\mathrm{SnO}_{2}$ surface of the particles/rods with generated radicals, which are known for a fast reaction. In comparison of silver-nanoparticlemodified 2D carbon materials, a huge difference in the range of detection is found for cvdG [117] and rGO [115]. This can be attributed to the smaller metallic particles (50 nm in size) on rGO compared to $200-\mathrm{nm}$ sized particles on cvdG. A reason for the bigger nanocrystals on the less defective carbon $2 \mathrm{D}$ material could be that defects act as nucleation sites, which allow better control of the reduction step. An outstanding low LOD in the ppt range was achieved by a vertical alignment of cvdG [58]. The authors highly attributed the hydrophobicity (water contact angle: $137^{\circ}$ ), the ultra-high specific surface area, exposed sharp edges, and the unique non-stacking three-dimensional geometry to be beneficial in reaching such high sensitivity. The drawback of this method is to be found in the device fabrication, which is rather time-consuming. For other gaseous analytes, the choice of the 2D material and the functionalization strategies can easily be derived from the examples shown for ammonia.

\section{Impedimetric, amperometric, voltammetric sensors}

Graphene-modified electrodes as impedimetric sensors are popular in determination of biomolecules, biomarker, proteins, or DNA. Mostly, the sensing mechanism depends on the blocking of the electrode upon analyte binding, which inhibits the interaction of the electrode with a redox marker present in the electrolyte. Table 2 presents graphene-based sensors to determine proteins or clinically relevant biomarkers by electrochemical impedance spectroscopy.

An impedimetric immunosensor was established by using cvdG. The protocol forsakes a physical adsorption of the antibody towards rabbit immunoglobulin $\mathrm{G}(\mathrm{IgG})$ onto a multilayered cvdG, grown on nickel [78]. Edges and wrinkles became present within the layered carbon material. The physical adsorption of anti-IgG is followed by a blocking step with BSA. Compared to the introduction of linker molecules, the non-destructive physical adsorption appeared to be superior as it leaves the $\mathrm{sp}^{2}$-hybridized structure of graphene intact, retaining the physical properties. Electrochemical impedance spectroscopy revealed an increase in the charge transfer resistance $\left(\mathrm{R}_{\mathrm{CT}}\right)$ from bare cvdG via an anti-IgG/cvdG to a BSA/ anti-IgG/cvdG assembly (Fig. 11). The incubation with rabbitIgG led to an even more enhanced $\mathrm{R}_{\mathrm{CT}}$, capable to determine the analyte with a LOD of $0.136 \mu \mathrm{g} \mathrm{mL} \mathrm{m}^{-1}$ IgG. Only after 7 days of storage, the signal response of this sensor drops to $48 \%$. This demonstrates a drawback of the physical adsorption of biomolecules in receptor design on $2 \mathrm{D}$ carbon materials.

Better stability can be achieved by attaching a receptor covalently. This is difficult for cvdG as it exhibits only functionalities upon an imperfect handling. A straightforward 
Table 2 Selection of various graphene-modified impedimetric sensors to quantify proteins and disease-relevant biomarkers

\begin{tabular}{|c|c|c|c|c|c|c|}
\hline Material & Modification & Analyte & Linear Range & LOD & Selectivity & Reference \\
\hline rGO & $\begin{array}{l}\text { MWCNT-Au } \\
\text { NPs-chitosan }\end{array}$ & Lysozyme & $0.02-250 \mathrm{pM}$ & $9 \mathrm{fM}$ & $\begin{array}{l}\text { BSA, HSA, Hb, thrombin, IgG, CytC, PSA, } \\
\text { enzymes }\end{array}$ & [123] \\
\hline rGO & MWCNT-Au NPs & PSA & $5-0.1 \mu \mathrm{g} \mathrm{mL}^{-1}$ & $1 \mathrm{pg} \mathrm{mL}^{-1}$ & BSA, $\mathrm{Hb}$, thrombin, IgG, lysozyme & {$[124]$} \\
\hline $\mathrm{rGO}$ & $\begin{array}{l}\text { SWCNT-Au } \\
\text { NPs-aptamer }\end{array}$ & HER2 & $\begin{array}{l}0.1 \mathrm{pg} \mathrm{mL}^{-1}- \\
\quad 1 \mathrm{ng} \mathrm{mL}^{-1}\end{array}$ & $50 \mathrm{fg} \cdot \mathrm{mL}^{-1}$ & BSA, BHb, thrombin, IgG, lysozyme, PSA & {$[125]$} \\
\hline cvdG & Anti-OVA & Ovalbumin & $1-0.1 \mathrm{pg} \mathrm{mL}^{-1}$ & $0.9 \mathrm{pg} \mathrm{mL}^{-1}$ & $\beta$-LG, lysozyme & [88] \\
\hline cvdG & Anti-CEA & CEA & $1.0-25.0 \mathrm{ng} \mathrm{mL}^{-1}$ & $0.23 \mathrm{ng} \mathrm{mL}^{-1}$ & KCl, CYFRA-21-1, CTnI & [83] \\
\hline cvdG & Anti-IgG & $\operatorname{IgG}$ & $0.1-100 \mu \mathrm{g} \mathrm{mL}^{-1}$ & $0.136 \mu \mathrm{g} \mathrm{mL} L^{-1}$ & $\mathrm{BSA}, \mathrm{Hb}$, avidin & {$[78]$} \\
\hline
\end{tabular}

$B S A$ bovine serum albumin, $C E A$ carcinoembryonic antigen, $(M W / S W) C N T$ multi-walled/single-walled carbon nanotubes, $C R P \mathrm{c}$ reactive protein, $C T n I$ cardiac troponin I, $C y t C$ cytochrome C, $(B) H b$ (bovine) hemoglobin, HER2 human epidermal growth factor, $H S A$ human serum albumin, $\beta$-LG $\beta$ lactoglobulin, $M b$ myoglobin, $P S A$ prostate-specific antigen

approach was developed by electrografting of 4aminobenzoic acid on cvdG to design a sensor for the determination of ovalbumin (OVA) [88]. Even though cvdG was supposed to convince with the exceptional electrical properties of a low-defective material, it was not taken into consideration that a covalent functionalization routine destructs the $\mathrm{sp}^{2}$-hybridized carbon lattice, changing the electronic properties of the material, i.e., by opening a bandgap. The LOD was $0.9 \mathrm{pg} \mathrm{mL}^{-1}$ OVA in a linear range of $1 \mathrm{pg} \mathrm{mL}^{-1}$ to $100 \mathrm{ng} \mathrm{mL}^{-1}$.

A comparison of electrochemically reduced graphene oxide and untreated graphene oxide was drawn to investigate the ability to improve the sensing performance towards DNA upon label-free electrical and enzymatic signal amplification [79]. The non-covalent modification of graphene layers with probe DNA increases the $R_{C T}$ value between redox marker and electrode surface due to electrostatic repulsion. Upon hybridization with the target DNA, the resistance increases even more. The enzyme exonuclease III recycles the sensor layer upon cleavage of the dsDNA (Fig. 12).

Investigations on DNA with various concentrations were performed for either GO modified electrodes (10 fM-1 nM
ssDNA) or rGO modified electrodes ( $5 \mathrm{aM}-1 \mathrm{nM}$ ssDNA). The GO-modified electrode revealed a LOD of $50 \mathrm{fM}$ DNA, whereas the LOD is significantly decreased to $10 \mathrm{aM}$ for $\mathrm{rGO}$ modified electrodes. Compared to GO which is almost an insulating material due to the enormous structural irregularities, highly conductive rGO is sensitive towards surface processes resulting in an enhanced change of $\mathrm{R}_{\mathrm{CT}}$ upon blocking and regeneration of the electrode material. A regenerated sensor layer did not suffer a loss of performance, whereas it became apparent that upon increased incubation time of the enzyme, artifacts regarding matrix adsorption as well as spontaneous enzyme deactivation might take place [79].

In contrast to glassy carbon (GC), rGO provides a high affinity to aromatic molecules as demonstrated by porphyrins, which easily attach by $\pi$-stacking to rGO. A metallic porphyrin-modified rGO impedimetric sensor was prepared to capture hepatitis C-DNA by a complementary ssDNA, which is linked to manganese(III) tetraphenylporphyrin (MnTPP) [80]. The non-covalent modification left the $\mathrm{sp}^{2}$ hybridized carbon lattice intact, maintaining high conductivity. In contrast to pyrene groups, porphyrins are able to incorporate an electrochemically active metal ion. The manganese
Fig. 11 Impedance behavior in the presence of a redox marker for cvdG (black), anti-IgG/cvdG (red), BSA/anti-IgG/cvdG (blue), and $\mathrm{IgG} / \mathrm{BSA} / \mathrm{anti}-\mathrm{IgG} / \mathrm{cvdG}$ (pink), respectively. Reproduced from [78] by permission of The Royal Chemical Society

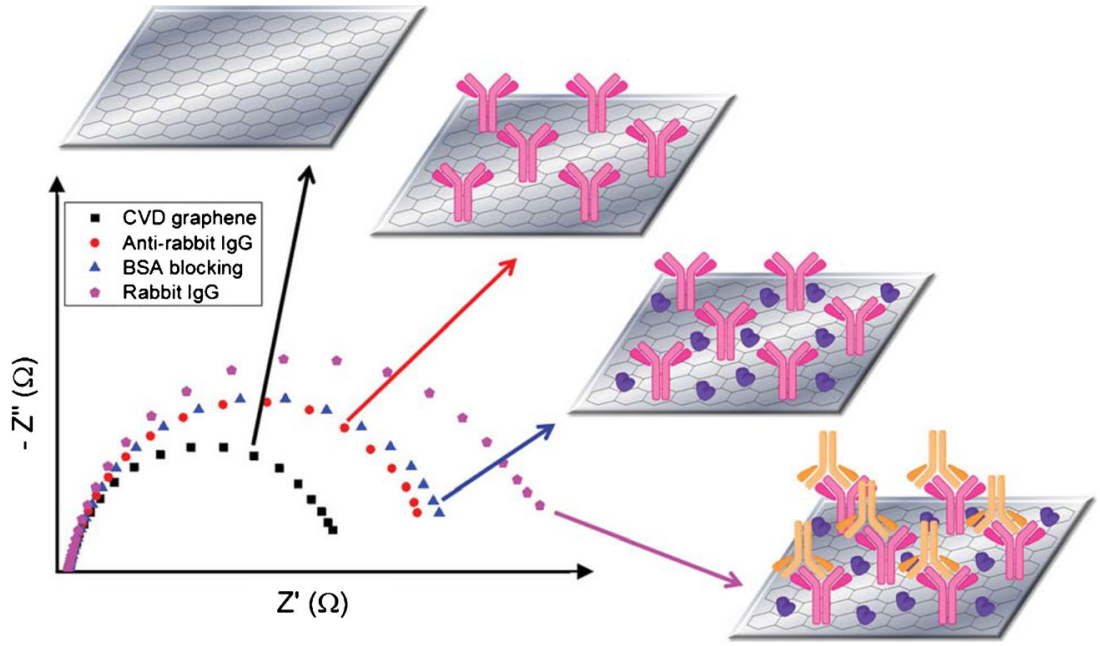


graphene oxide on electrode

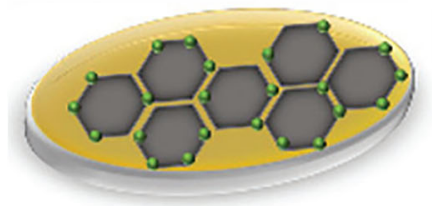

oxygen functional groups

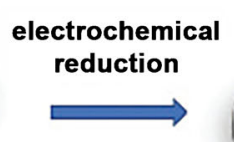

high impedance

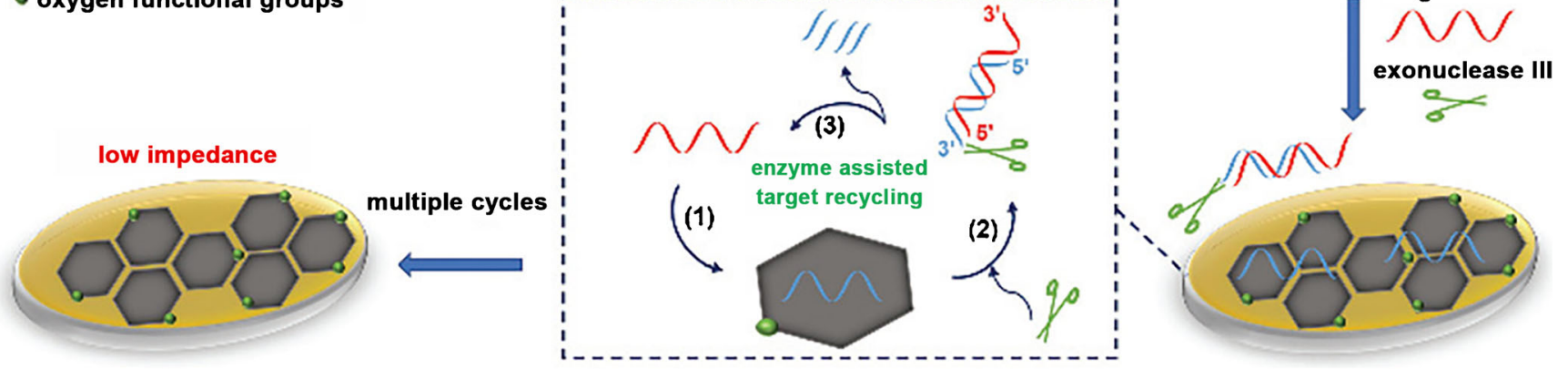

Fig. 12 Scheme of an impedimetric sensor based on rGO, which is modified by adsorption of probe DNA. The determination of complementary target DNA is accompanied by enzyme-assisted sensor recycling. Reproduced from [79] by permission of The Royal Society of Chemistry

ion served to monitor the stability of the porphyrin linker attached to the electrode during electrochemical measurements. The use of rGO as supporting material prevented the MnTPP from detaching, in contrast to a glassy carbon electrode (GCE). An increased electron transfer attributed to graphene's high surface area as well as the short distance between graphene and porphyrin result in a sufficient sensor performance [80].

Table 3 presents impedimetric graphene-modified sensors that determine DNA strands, potentially applicable in clinical diagnosis to identify viruses, bacteria, as well as relevant biomarkers. Many allotropes from the pool of graphene materials can be found as sensor material, but the reduced graphene oxide is the most frequently used compound, due to the well-established fabrication protocols. The functional groups present at the material's surface enable easy functionalization by deposition of conductive polymers [126, 127], liposomes [128], metallic nanoparticles [129-132], or porphyrins [80] to pave the way for enhanced analysis strategies.

In contrast to frequency-dependent impedance spectroscopy, which monitors binding events in an equilibrium, timedependent sensing techniques, e.g., voltammetry and amperometry, are attractive to investigate induced electrochemical reactions.

Numerous exfoliation protocols strive for the preparation of graphene materials with a low number of defects to come close to the ideal graphene. For time-dependent electrochemical sensing techniques, the presence and number of defects within the graphene affects their electrochemical activity. The defect-dependent sensing capability of the $2 \mathrm{D}$ carbon compounds generated by sonication was investigated upon the determination of phenolic compounds. The quality of the carbon materials ranges from a low amount of defects present within the structure to graphene compounds, which were anodized to provide additional functional groups [71]. NMPdispersed-graphite powder was exfoliated in a sonication bath $(40 \mathrm{kHz}, 100 \mathrm{~W})$ for $48 \mathrm{~h}$ yielding graphene sheets. For a comparative study, GO was synthesized by a modified Hummers' method. Glassy carbon electrodes were modified by drop-casting of graphene and drying under an infrared lamp. The LPE graphene-modified electrodes were anodized $(1.8 \mathrm{~V}$ for $2 \mathrm{~min})$ in acetate buffer $(\mathrm{pH} 5.6)$. Atomic force microscopy revealed the roughest surface for sonicationderived graphene-modified GCE, potentially exhibiting the highest number of active sites. Differential pulse voltammetry (DPV) for all phenolic compounds revealed none or very weak oxidation peaks for GCE and GO-modified electrodes. The oxidation peaks are enhanced and shifted to more negative potentials for graphene/GCE and anodized graphene/ GCE. The LODs are calculated to be $12 \mathrm{nM}, 15 \mathrm{nM}, 10 \mathrm{nM}$, and $40 \mathrm{nM}$ for hydroquinone, catechol, 4-chlorophenol, and 4-nitrophenol, respectively [71]. The electrochemical sensor performance of differently prepared graphene compounds was examined for a wide range of electrochemically active analytes like biomolecules, synthetic colorants, and phenolic compounds (4-chlorophenol, 4-nitrophenol)) using DPV. The plain GCE was not able to determine the analytes at low concentrations, but as the amount of defects increased within the graphene materials, the oxidation current of the different analytes increases [70]. Although the addition of salts might enhance the exfoliation efficiency of graphene via LPE, one of the advantages of fabrication by ultrasound is the possibility to prepare 2D materials in appropriate medium without the need of any additives, potentially influencing the physical behavior of the material. Comparing the detection limits of salt-assisted exfoliated graphene to sonicated graphene subsequently 
Table 3 Impedimetric graphene-modified sensors to determine ssDNA. Every sensor layer is additionally modified with a specific capture probe DNA

\begin{tabular}{|c|c|c|c|c|c|c|}
\hline Material & Modification & Nucleotides & Linear range & LOD & Selectivity & Reference \\
\hline GO & Chitosan & 21 & $10 \mathrm{fM}-10 \mathrm{nM}$ & $3.6 \mathrm{fM}$ & Mismatched & {$[133]$} \\
\hline $\begin{array}{l}\text { carboxylated } \\
\text { graphene-nanoflakes }\end{array}$ & APTMS-ZnO & 17 & $0.1 \mathrm{fM}-1 \mu \mathrm{M}$ & $0.1 \mathrm{fM}$ & $\begin{array}{l}\text { Mismatched, } \\
\text { non-complementary }\end{array}$ & {$[134]$} \\
\hline $\mathrm{rGO}$ & Exonuclease III & 23 & $50 \mathrm{aM}-1 \mathrm{nM}$ & $10.0 \mathrm{aM}$ & Mismatched & [79] \\
\hline $\mathrm{rGO}$ & Liposome & 24 & $1 \mu \mathrm{M}-1 \mathrm{fM}$ & $10.0 \mathrm{aM}$ & $\begin{array}{l}\text { Mismatched, } \\
\text { non-complementary }\end{array}$ & {$[128]$} \\
\hline $\mathrm{rGO}$ & $\mathrm{Au}$ NPs-PABA & 20 & $0.1 \mathrm{fM}-10 \mathrm{nM}$ & $37 \mathrm{aM}$ & Mismatched & [129] \\
\hline rGO & PANI & 23 & $0.5 \mathrm{fM}-0.1 \mathrm{nM}$ & $0.1 \mathrm{fM}$ & $\begin{array}{l}\text { Mismatched, } \\
\text { non-complementary }\end{array}$ & {$[126]$} \\
\hline rGO & $\mathrm{PPy}-\mathrm{CO}_{2} \mathrm{H}$ & 19 & $10 \mathrm{fM}-10 \mathrm{nM}$ & $3 \mathrm{fM}$ & $\begin{array}{l}\text { Mismatched, } \\
\text { non-complementary }\end{array}$ & {$[127]$} \\
\hline $\mathrm{rGO}$ & $\begin{array}{l}\mathrm{ZrO}_{2} \text {-hairpin probe } \\
\text { DNA }\end{array}$ & 22 & $10 \mathrm{fM}-0.1 \mathrm{nM}$ & $4.3 \mathrm{fM}$ & $\begin{array}{l}\text { Mismatched, } \\
\text { non-complementary }\end{array}$ & [135] \\
\hline rGO & Nafion & - & $\begin{array}{l}0.1 \\
\mathrm{pM}-0.1 \mathrm{nM}\end{array}$ & $23 \mathrm{fM}$ & Mismatched & {$[136]$} \\
\hline $\mathrm{rGO}$ & $\mathrm{Au}$ NPs & 30 & 0.1 & $36 \mathrm{fM}$ & $\begin{array}{l}\text { Mismatched, } \\
\text { non-complementary }\end{array}$ & {$[130]$} \\
\hline $\mathrm{rGO}$ & MnTPP & 25 & $0.1 \mathrm{fM}-10 \mathrm{pM}$ & $61 \mathrm{fM}$ & $\begin{array}{l}\text { Mismatched, } \\
\text { non-complementary }\end{array}$ & {$[80]$} \\
\hline $\mathrm{rGO}$ & $\mathrm{Au}$ NPs & 18 & $10 \mathrm{nM}-20 \mu \mathrm{M}$ & $0.18 \mathrm{nM}$ & Non-complementary & {$[131]$} \\
\hline cvdG & oxygenated & 15 & $2 \mathrm{aM}-1 \mathrm{pM}$ & $1.0 \mathrm{aM}$ & $\begin{array}{l}\text { Mismatched, } \\
\text { non-complementary }\end{array}$ & {$[137]$} \\
\hline $\mathrm{ecG}$ & - & - & $0.2-5 \mathrm{pg} \mathrm{mL}^{-1}$ & $0.68 \mathrm{pg} \mathrm{mL}^{-1}$ & - & {$[138]$} \\
\hline Ultrasound-exfoliated graphene & $\mathrm{ZnO}$ & 25 & $10 \mathrm{pM}-1 \mu \mathrm{M}$ & $4.3 \mathrm{pM}$ & $\begin{array}{l}\text { Mismatched, } \\
\text { non-complementary }\end{array}$ & {$[132]$} \\
\hline
\end{tabular}

APTMS (3-aminopropyl)trimethoxysilane, $P A B A$ 4-aminobenzoic acid, PANI polyaniline (emeraldine salt)

anodized, the LOD for 4-chlorophenol and 4-nitrophenol was increased by a factor of two and of six, respectively. The extended sonication time seems to be a promising alternative to prepare graphene compounds, instead of using additives, potentially influencing the material.

Electrochemical graphite exfoliation is predestined for simplification as the preparation procedure and material functionalization can be combined to one step, which was proved for a graphene-porphyrin compound. Graphite was exfoliated electrochemically with porphyrin as intercalant, simultaneously functionalizing graphene flakes by $\pi$-interaction, introducing an oxidizing agent for catechol [81]. Apparently, the material exfoliated by means of additional salts weakens the performance of the established electrochemical sensor with regard to liquid-phase exfoliation of graphene derived solely by exfoliation in appropriate solvent. The generation of 2D-based heterostructures incorporating catalytically active compounds is required to improve the performance of sensors towards analyte determination.

The design of improved electrochemical sensors envisions the hybridization of electrocatalytic active groups with graphene substrates. Besides the functionalization of graphene with carbon allotropes by $\pi$-stacking, highly attractive became the decoration with electrocatalytic active metallic nanoparticles (NPs). They provide a suitable substitute to natural enzymes, as they are more stable and are less prone to operation and environmental conditions. Metallic nanoparticles combine easily with carbon materials upon hydrothermal route or by direct electrodeposition onto the substrate of choice [86, 124, 125, 129, 132, 134, 139-143]. For successful analyte determination upon catalytic reaction, the achievement of homogeneously distributed small metallic NPs exhibiting a large electrical active surface is crucial. Nevertheless, it became apparent that deposited NPs tend to agglomerate on polycrystalline materials, i.e., GC due to inhomogeneous charge distribution. This drawback is targeted by using graphene as supporting material, which prevents the particles from agglomeration resulting in homogeneously distributed monodisperse NPs creating an electrochemical synergy of the carbon-metal-interface [144].

The diameter of nanoparticles is crucial towards the electrocatalytic behavior, as the potentials of redox reactions can be shifted by the nanoparticle's size and shape. The size of the particles can be either modulated by applied deposition voltage or deposition time, as shown in Fig. 13.

Tables 4 and 5 provide an overview of graphene-modified electrodes targeting hydrogen peroxide or glucose, both frequently determined in bioanalysis. To enhance the sensitivity and selectivity, catalytically active metals replaced enzymes almost completely influencing the operation potential. An 
a
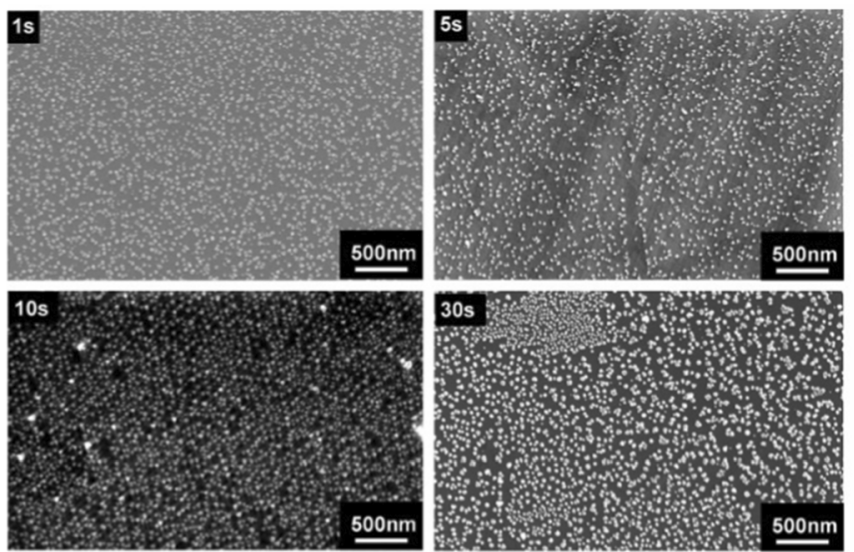

Fig. 13 SEM images of AgNPs modified cvdG for $1 \mathrm{~s}, 5 \mathrm{~s}, 10 \mathrm{~s}$, and $30 \mathrm{~s}$ in $0.2 \mathrm{M} \mathrm{KNO}_{3}$ containing $0.7 \mathrm{mM} \mathrm{AgNO}_{3}$ stepping the potential from 0 to $-0.4 \mathrm{~V}$ (a). AgNPs were deposited on cvdG at potentials of $-0.2 \mathrm{~V}$, -

amperometric gold-GO-based sensor was prepared by simultaneous electrodeposition of $\mathrm{GO}$ containing $\mathrm{HAuCl}_{4}$, forming a AuNPs-modified rGO hybrid [86]. Gold nanoparticles were chosen as catalyst due to its stability and operation in neutral medium. An aqueous dispersion of GO was electrodeposited on gold electrodes by application of a potential of $-30 \mathrm{~V}$ for $20 \mathrm{~min}$, reducing GO. The graphene support is necessary to stabilize AuNPs, which tend to agglomerate otherwise. Additionally, graphene enhances the glucose oxidation process. Amperometric measurements were performed in phosphate buffer ( $\mathrm{pH}$ 7.4) at a potential of $0 \mathrm{~V}$ vs. $\mathrm{Ag} / \mathrm{AgCl}$, subsequently adding glucose with increasing concentration, exhibits a LOD of $12 \mu \mathrm{M}$.

A ternary hybrid composed of graphene, AgNPs and Nafion, targets the determination of $\mathrm{H}_{2} \mathrm{O}_{2}$ [30]. The b
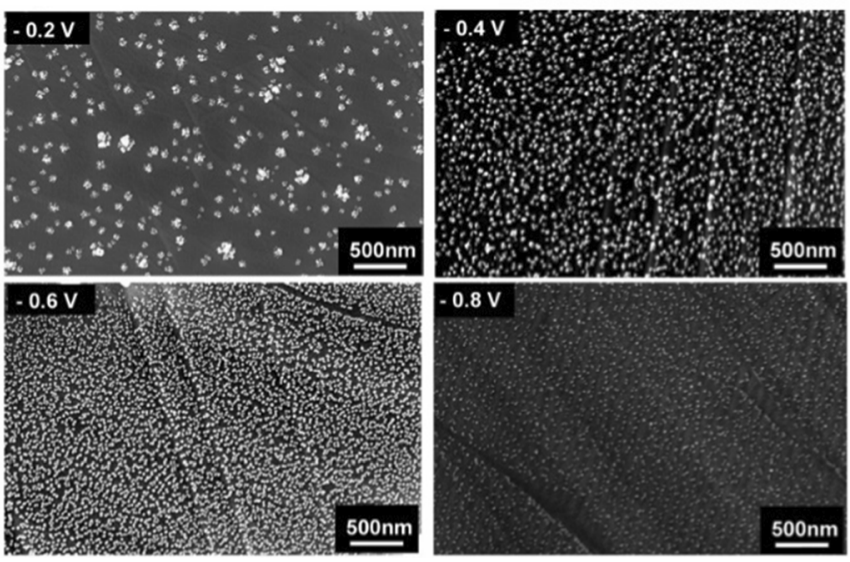

$-0.8 \mathrm{~V}$

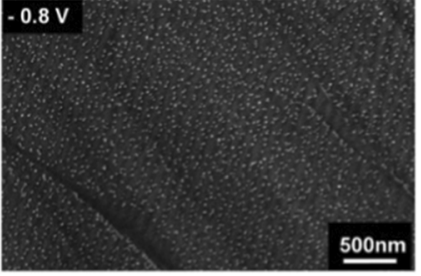

$0.4 \mathrm{~V},-0.6 \mathrm{~V}$, and $-0.8 \mathrm{~V}$, respectively, for $30 \mathrm{~s}(\mathbf{b})$. All potentials are given vs. $\mathrm{Ag} / \mathrm{AgCl}$. Adapted from [141] with permission from The Royal Society of Chemistry

combination of material enhances the surface area, the conductivity, and leads to stable compounds. Silver pose electrocatalytic activity but tend to oxidation, which requires the protective Nafion layer. The hydrothermal synthesis of the heterostructure was accomplished by a one-pot approach, mixing the precursor materials, GO dispersion, Nafion solution, and $\mathrm{AgNO}_{3}$. Glassy carbon electrodes were modified by drop-casting of rGO-Nafion-AgNPs. Cyclic voltammetric studies showed that an excessive AgNPs decoration led to the deterioration of the reduction ability of the sensor, as the aggregation of AgNPs reduces the electrocatalytic active sites of the material. Amperometric sensing was performed by applying a potential of $-0.65 \mathrm{~V}$ revealing a LOD of $0.53 \mu \mathrm{M}$ $\mathrm{H}_{2} \mathrm{O}_{2}$, with a high selectivity for $\mathrm{H}_{2} \mathrm{O}_{2}$ compared to the five times increased concentration of urea, glucose, dopamine, uric

Table 4 Amperometric sensors based on graphene-modified electrodes to determine glucose. All potentials were measured against $\mathrm{Ag} / \mathrm{AgCl}$ when not stated otherwise

\begin{tabular}{|c|c|c|c|c|c|c|}
\hline Material & Modification & Potential/V & Linear range & $\begin{array}{l}\mathrm{LOD} / \\
\mu \mathrm{M}\end{array}$ & Selectivity & Reference \\
\hline LIG & $\mathrm{Cu}$ NPs & $-0.4(\mathrm{SCE})$ & $1-4.54 \mu \mathrm{M}$ & 0.35 & AA, UA, DA, AP, Fru, Lac, Suc & {$[145]$} \\
\hline N-rGO & $\mathrm{Cu}$ NPs & 0.6 & $0.01-100 \mu \mathrm{M}$ & 0.01 & AA, UA, DA, Fru, Lac, Suc & {$[146]$} \\
\hline $\mathrm{N}-\mathrm{rGO}$ & $\mathrm{Ni}(\mathrm{OH})_{2}$ nanorods & 0.45 & $0.5-11.5 \mu \mathrm{M} ; 11.5-240 \mu \mathrm{M}$ & 0.12 & AA, UA, DA, Fru, Lac, Suc & {$[147]$} \\
\hline $\mathrm{rGO}$ & $\mathrm{Cu}$ NPs-PANI & 0.5 (SCE) & $1 \mu \mathrm{M}-0.96 \mathrm{mM}$ & 0.27 & AA, UA, DA, Lac, Suc & [148] \\
\hline rGO & $\mathrm{Cu}$ nanoflower & 0.6 & $2 \mu \mathrm{M}-2 \mathrm{mM} ; 2-13 \mathrm{mM}$ & 0.5 & $\mathrm{AA}, \mathrm{UA}, \mathrm{DA}, \mathrm{NaNO}_{3}$ & [143] \\
\hline rGO & $\mathrm{Ag}-\mathrm{CuO} \mathrm{NPs}$ & 0.6 & $0.01-28 \mathrm{mM}$ & 0.76 & AA, UA, DA, Gal, Lac, Suc & [139] \\
\hline rGO & Ni-doped $\mathrm{MoS}_{2} \mathrm{NPs}$ & 0.55 & $0.005-8.2 \mathrm{mM}$ & 2.7 & AA, UA, DA, AP & [149] \\
\hline rGO & PtAu NPs -GOx-chitosan & 0.45 & $0.005-2.4 \mathrm{mM}$ & 5 & AA, UA, AP & [142] \\
\hline $\mathrm{rGO}$ & $\mathrm{Au}$ NPs & 0 & $0.05-14 \mathrm{mM} ; 14-42 \mathrm{mM}$ & 12 & AA, UA, DA, urea & {$[86]$} \\
\hline CVD & $\mathrm{Au} \mathrm{NPs}$ & 0 & $6 \mu \mathrm{M}-28.5 \mathrm{mM}$ & 1 & & {$[150]$} \\
\hline oxygenated-CVD & GOx-Nafion & -0.5 & $0.4-2 \mathrm{mM}$ & 124.2 & & {$[151]$} \\
\hline
\end{tabular}

$A A$ ascorbic acid, AP 4-acetamidophenol, DA dopamine, Fru fructose, Gal galactose, Lac lactose, LIG laser-induced graphene, PANI polyaniline (emeraldine salt), Suc sucrose, $U A$ uric acid 
Table 5 Amperometric sensors based on graphene-modified electrodes to determine hydrogen peroxide. All potentials were measured against Ag/ $\mathrm{AgCl}$, when not stated otherwise

\begin{tabular}{|c|c|c|c|c|c|c|}
\hline Material & Modification & Potential/V & Linear range & $\begin{array}{l}\mathrm{LOD} / \\
\mu \mathrm{M}\end{array}$ & Selectivity & Reference \\
\hline LIG & Ag NPs & -0.5 & $0.1-10 \mathrm{mM}$ & 7.9 & AA, Glu, & {$[152]$} \\
\hline $\begin{array}{l}\text { 3D-N-doped } \\
\text { rGO }\end{array}$ & $\begin{array}{l}\mathrm{NiCo}_{2} \mathrm{O}_{4} \\
\text { nanoflowers }\end{array}$ & 0.5 & $1-510 \mu \mathrm{M}$ & 0.136 & AA, UA, DA & [153] \\
\hline rGO & nAPAMSs & -0.5 & $0.005-4 \mathrm{mM}$ & 0.008 & AA, UA, AP, Glu & {$[35]$} \\
\hline $\mathrm{rGO}$ & Fe NPs & -0.5 & $0.1 \mu \mathrm{M}-2.15 \mathrm{mM}$ & 0.056 & AA, UA, DA, CT, Glu & {$[154]$} \\
\hline $\mathrm{rGO}$ & Ferumoxytol-Pt NPs & 0.1 & $\begin{array}{l}0.4-10 \mu \mathrm{M} ; 0.0075-4.3 \mathrm{mM} \\
\quad 4.9-10.8 \mathrm{mM}\end{array}$ & 0.38 & AA, DA, Cys, GSH, Fru & {$[155]$} \\
\hline $\mathrm{rGO}$ & $\mathrm{Cu}_{2} \mathrm{O}-\mathrm{PANI}$ & $-0.2(\mathrm{SCE})$ & $0.8 \mu \mathrm{M}-12.78 \mathrm{mM}$ & 0.5 & AA, UA, Glu & {$[140]$} \\
\hline rGO & Nafion-Ag NPs & $-0.6(\mathrm{SCE})$ & $1-30 \mathrm{mM}$ & 0.54 & AA, UA, DA, Glu, urea & {$[30]$} \\
\hline CVD & $\mathrm{Au}$ NPs & 0.5 & $25 \mathrm{nM}-1.5 \mathrm{mM}$ & 0.01 & - & {$[156]$} \\
\hline CVD & Pd NPs & -0.12 & $4 \mu \mathrm{M}-13.5 \mathrm{mM}$ & 1.5 & - & {$[157]$} \\
\hline CVD & $\mathrm{Fe}_{3} \mathrm{O}_{4} \mathrm{NPs}$ & 0.7 & $12.5-112.5 \mu \mathrm{M}$ & 4.4 & - & {$[158]$} \\
\hline Sono-ecG & - & -0.4 & $0.02-2.9 \mathrm{mM}$ & 2.67 & AA, UA & [159] \\
\hline
\end{tabular}

$A A$ ascorbic acid, $A P$ 4-acetamidophenol, $C y s$ cysteine, DA dopamine, Fru fructose, GOx glucose oxidase, GSH glutathione, $L a c$ lactose, $L I G$ laserinduced graphene, $n A P A M S$ nano Au and Pt alloy microsphere, PANI polyaniline (emeraldine salt), Suc sucrose, UA uric acid

acid, and ascorbic acid [30]. In contrast, a $\mathrm{H}_{2} \mathrm{O}_{2}$ sensor was prepared consisting of a heterostructure, decorated by microspheres of noble metals, Au and Pt, supported by rGO [35]. Reduced graphene oxide convinced as support due to higher conductivity and better stability. Furthermore, the lattice defects and functional groups pose attractive sites for deposition of metallic particles, which prevent them from aggregation. The solutions of $\mathrm{GO}, \mathrm{H}_{2} \mathrm{PtCl}_{6}$, and $\mathrm{HAuCl}_{4}$ were mixed in equal molar ratio adding $\mathrm{NaBH}_{4}$ to trigger the reduction reaction. A GC electrode was drop-coated with $\mathrm{rGO} / \mathrm{Au} / \mathrm{Pt}$. To detect $\mathrm{H}_{2} \mathrm{O}_{2}$ amperometrically, a potential of $80 \mathrm{mV}$ vs. $\mathrm{Ag} /$ $\mathrm{AgCl}$ was applied, subsequently injecting the analyte into PBS (pH 7) resulting in a low LOD of $0.008 \mu \mathrm{M}$ [35]. Apparently, even though noble metals are more expensive, they provide an enhanced electrocatalytic behavior in combination with graphene due to synergistic effects.

\section{Conclusion}

Two-dimensional carbon materials have been intensively studied regarding synthesis, fabrication, and their implementation in electrochemical sensors. The fact that this class of nanomaterial is much more than a $\mathrm{sp}^{2}$-hybridized honeycomblattice of carbon atoms becomes vivid, when investigating the physical and chemical properties of the material, depending on the exfoliation technique. It can be stated that the preparation method guides the performance of the sensor material due the different intrinsic characteristics.

The variances originate from defects distributed within the carbon lattice, layer inconsistencies, oxygen functional groups, and adatoms. The still ongoing development of fabrication methods for 2D carbon materials in the last years' aims for a high-yield production with a reproducible quality. Overcoming the weak interlayer van-der-Waals forces results in the delamination of the bulk material, yielding robust and flexible nanomaterial flakes due to strong intralayer forces $[40,160]$.

In 2018, the group of Castro-Neto has investigated the quality of graphene supplied from 60 different producers with the result that the quality of these materials is rather poor, and this is claimed as one of the key issues for the slow development of applications [161]. Especially for liquid-dispersed graphene, it is difficult to produce these batches with high reproducibility in quality. There is also information missing on the aging of such dispersions restacking of the material. In contrast to dispersions, cvdG shows better reproducibility. It is expected that challenges in reproducibility can be overcome by better characterization techniques [161].

The modification of the 2D materials are easily achieved either by covalent or non-covalent functionalization to improve the selectivity of the sensor $[75,76]$. On the one hand, covalent modifications are reported to damage the $\mathrm{sp}^{2}$-hybridized carbon system of graphene. On the other hand, the linkage of active biomolecules might become an issue as the natural structure of the biomolecule can be disrupted followed by a loss of activity [102].

Numerous sensors were reported for an enormous variety of analytes based on 2D materials beyond the scope of this review. Different exfoliation techniques yield 2D carbon materials of a diverse structure, which consequently exhibits altered physical properties. Graphene, derived by CVD, is rather integrated in FETs or chemiresistors, as these sensors base on the change of the intrinsic electrical characteristics of the sensing layer upon analyte adsorption. The advantage of this material is claimed to be the intact $\mathrm{sp}^{2}$-hybridized carbon lattice, 
but for most electrochemical sensors, this is not a limitation so far. It is to point out that cvdG is prone to an unintentional introduction of non-reproducible defects, i.e., smallest variations of the processing parameters, complex transfer protocols inducing ionic impurities, and structural defects, deteriorating the physical and chemical properties. Besides the rather highquality cvdG, synthetically derived rGO is widest applied as sensor layer since it is either produced in an ordinary laboratory or purchased from the growing market of suppliers offering graphene materials up to a liter-range. A large defect density is distributed along the material's basal planes. Even though this term has a negative connotation, those structural defects do not pose a drawback when it comes to sensing applications. Quite the contrary, the defects are resembled as active functional groups, preferably interacting with a potential analyte, when applied as sensor surface. Not any other material was used as frequently as reduced graphene oxide in sensor design, due to the simplicity of the material and its physicochemical properties. Additionally, the oxygen moieties enable the dispersibility of rGO in water.

In terms of easily derived, low-cost, liquid processable material, one has to keep in mind the LPE-process of graphite. The exfoliation via sonication or shear exfoliation is widely performed either in toxic, high-boiling point, organic solvents with a matching surface tension to the material or in aqueous solution with a stabilizing surfactant. Two-dimensional materials are obtained without a chemical change in the basal plane of their structure, but with varying flake size and number of layers from mono- to multi-layered compounds. The diverse surface chemistry often affects the physical properties in a non-reproducible way. The mechanical exfoliation process may not introduce structural irregularities within the carbon layer, yet the number of defects increase upon formation of smaller flakes dominated by edge-planes. Electrochemical exfoliation is performed in aqueous solution using inorganic salts as intercalating species upon application of a high voltage. A bonus is the possibility of direct functionalization during exfoliation. Many reports exist on how to exfoliate 2D materials, but little is derived on the sensing behavior, especially when the morphology of the materials changes upon variation of the delamination process. Nevertheless, the reported LPE-derived materials applied in impedimetric or amperometric sensors revealed promising results. Future trends envision the use of all carbon-fabricated wearable electrochemical sensors. For a direct application on the skin, deeper understanding of the toxicity of each class of 2D carbon materials is still needed. The sustainability of the preparation procedures is barely addressed even though the growing demand of production and processing procedures result in an enhanced consumption of resources.

A deeper understanding of the electrochemical properties of the 2D carbon materials has to be obtained to unravel the question, whether a graphene material suits the requirements of the potential sensor. As stated before, the widest applied materials for sensor development were contrary materials, cvdG and rGO, known for either high-quality or defective graphene. Instead of implementing the materials according to their unique features, it was found that the intact $\mathrm{sp}^{2}$-hybridized carbon system of cvdG was intentionally destructed by introduction of $\mathrm{sp}^{3}$-hybridized functionalities. To become an essential part in mass-produced electrochemical sensors, the system integration must be compatible to already existing complementary metal-oxide-semiconductor (CMOS) technologies [162]. It is vital to understand which material will meet the sensor's need to improve its performance. The electrochemical features have to be explored and further correlated to the chemical structure of the material. The obtained fundamental knowledge of physical and chemical correlations might be the key to tune the material's properties directly to the special requirements, which would lead to much smarter sensors in the future.

Funding Information Open Access funding provided by Projekt DEAL.

\section{Compliance with ethical standards}

Conflict of interest The author (s) declare that they have no competing interests.

Open Access This article is licensed under a Creative Commons Attribution 4.0 International License, which permits use, sharing, adaptation, distribution and reproduction in any medium or format, as long as you give appropriate credit to the original author(s) and the source, provide a link to the Creative Commons licence, and indicate if changes were made. The images or other third party material in this article are included in the article's Creative Commons licence, unless indicated otherwise in a credit line to the material. If material is not included in the article's Creative Commons licence and your intended use is not permitted by statutory regulation or exceeds the permitted use, you will need to obtain permission directly from the copyright holder. To view a copy of this licence, visit http://creativecommons.org/licenses/by/4.0/.

\section{References}

1. Yang W, Ratinac KR, Ringer SP, Thordarson P, Gooding JJ, Braet F (2010) Carbon nanomaterials in biosensors: should you use nanotubes or graphene? Angew Chem Int Ed 49:2114-2138

2. Novoselov KS, Geim AK, Morozov SV, Jiang D, Zhang Y, Dubonos SV, Grigorieva IV, Firsov AA (2004) Electric field effect in atomically thin carbon films. Science 306:666-669

3. Ferrari AC, Bonaccorso F, Fal'ko V, Novoselov KS, Roche S, Bøggild P, Borini S, Koppens FHL, Palermo V, Pugno N, Garrido JA, Sordan R, Bianco A, Ballerini L, Prato M, Lidorikis E, Kivioja J, Marinelli C, Ryhänen T, Morpurgo A, Coleman JN, Nicolosi V, Colombo L, Fert A, Garcia-Hernandez M, Bachtold A, Schneider GF, Guinea F, Dekker C, Barbone M, Sun Z, Galiotis C, Grigorenko AN, Konstantatos G, Kis A, Katsnelson M, Vandersypen L, Loiseau A, Morandi V, Neumaier D, Treossi E, Pellegrini V, Polini M, Tredicucci A, Williams GM, Hong BH, Ahn J-H, Kim JM, Zirath H, van Wees BJ, van der Zant H, 
Occhipinti L, Di Matteo A, Kinloch IA, Seyller T, Quesnel E, Feng X, Teo K, Rupesinghe N, Hakonen P, Neil SRT, Tannock Q, Löfwander T, Kinaret J (2015) Science and technology roadmap for graphene, related two-dimensional crystals, and hybrid systems. Nanoscale 7:4598-4810

4. Zhang H, Chhowalla M, Liu Z (2018) 2D Nanomaterials: Graphene and transition metal dichalcogenides. Chem Soc Rev 47:3015-3017

5. Benck JD, Pinaud BA, Gorlin Y, Jaramillo TF (2014) Substrate selection for fundamental studies of electrocatalysts and photoelectrodes: inert potential windows in acidic, neutral, and basic electrolyte. PLoS One 9:e107942

6. Zhou M, Zhai Y, Dong S (2009) Electrochemical sensing and biosensing platform based on chemically reduced graphene oxide. Anal Chem 81:5603-5613

7. Ferreira M, Varela H, Torresi RM, Tremiliosi-Filho G (2006) Electrode passivation caused by polymerization of different phenolic compounds. Electrochim Acta 52:434-442

8. Sha R, Puttapati SK, Srikanth VV, Badhulika S (2017) Ultrasensitive phenol sensor based on overcoming surface fouling of reduced graphene oxide-zinc oxide composite electrode. J Electroanal Chem 785:26-32

9. Zheng D, Hu H, Liu X, Hu S (2015) Application of graphene in electrochemical sensing. Curr Opin Colloid Interface Sci 20:383405

10. Backes C, Abdelkader AM, Alonso C, Andrieux-Ledier A, Arenal R, Azpeitia J, Balakrishnan N, Banszerus L, Barjon J, Bartali R, Bellani S, Berger C, Berger R, Ortega MMB, Bernard C, Beton $\mathrm{PH}$, Beyer A, Bianco A, Bøggild P, Bonaccorso F, Barin GB, Botas C, Bueno RA, Carriazo D, Castellanos-Gomez A, Christian M, Ciesielski A, Ciuk T, Cole MT, Coleman J, Coletti C, Crema L, Cun H, Dasler D, de Fazio D, Díez N, Drieschner S, Duesberg GS, Fasel R, Feng X, Fina A, Forti S, Galiotis C, Garberoglio G, García JM, Garrido JA, Gibertini M, Gölzhäuser A, Gómez J, Greber T, Hauke F, Hemmi A, Hernandez-Rodriguez I, Hirsch A, Hodge SA, Huttel Y, Jepsen PU, Jimenez I, Kaiser U, Kaplas T, Kim H, Kis A, Papagelis K, Kostarelos K, Krajewska A, Lee K, Li C, Lipsanen H, Liscio A, Lohe MR, Loiseau A, Lombardi L, Francisca López M, Martin O, Martín C, Martínez L, Martin-Gago JA, Ignacio Martínez J, Marzari N, Mayoral Á, McManus J, Melucci M, Méndez J, Merino C, Merino P, Meyer AP, Miniussi E, Miseikis V, Mishra N, Morandi V, Munuera C, Muñoz R, Nolan H, Ortolani L, Ott AK, Palacio I, Palermo V, Parthenios J, Pasternak I, Patane A, Prato M, Prevost H, Prudkovskiy V, Pugno N, Rojo T, Rossi A, Ruffieux P, Samorì P, Schué L, Setijadi E, Seyller T, Speranza G, Stampfer C, Stenger I, Strupinski W, Svirko Y, Taioli S, Teo KBK, Testi M, Tomarchio F, Tortello M, Treossi E, Turchanin A, Vazquez E, Villaro E, Whelan PR, Xia Z, Yakimova R, Yang S, Yazdi GR, Yim C, Yoon D, Zhang X, Zhuang X, Colombo L, Ferrari AC, Garcia-Hernandez M (2020) Production and processing of graphene and related materials. J Phys Condens Matter 7:22001

11. Tan C, Cao X, Wu X-J, He Q, Yang J, Zhang X, Chen J, Zhao W, Han S, Nam G-H, Sindoro M, Zhang H (2017) Recent advances in ultrathin two-dimensional nanomaterials. Chem Rev 117:62256331

12. Bonaccorso F, Bartolotta A, Coleman JN, Backes C (2016) 2Dcrystal-based functional inks. Adv Mater 28:6136-6166

13. Bonaccorso F, Lombardo A, Hasan T, Sun Z, Colombo L, Ferrari AC (2012) Production and processing of graphene and 2D crystals. Mater Today 15:564-589

14. Gupta A, Sakthivel T, Seal S (2015) Recent development in 2D materials beyond graphene. Prog Mater Sci 73:44-126

15. Anichini C, Czepa W, Pakulski D, Aliprandi A, Ciesielski A, Samorì $\mathrm{P}$ (2018) Chemical sensing with 2D materials. Chem Soc Rev 47:4860-4908
16. Reina G, González-Domínguez JM, Criado A, Vázquez E, Bianco A, Prato M (2017) Promises, facts and challenges for graphene in biomedical applications. Chem Soc Rev 46:4400-4416

17. Yadav N, Lochab B (2019) A comparative study of graphene oxide: Hummers, intermediate and improved method. FlatChem 13:40-49

18. Brodie BC (1859) XIII. On the atomic weight of graphite. Philos Trans R Soc Lond 149:249-259

19. Staudenmaier L (1898) Verfahren zur Darstellung der Graphitsäure. Ber Dtsch Chem Ges 31:1481-1487

20. Hummers WS, Offeman RE (1958) Preparation of graphitic oxide. J Am Chem Soc 80:1339

21. Botas C, Álvarez P, Blanco P, Granda M, Blanco C, Santamaría R, Romasanta LJ, Verdejo R, López-Manchado MA, Menéndez R (2013) Graphene materials with different structures prepared from the same graphite by the Hummers and Brodie methods. Carbon 65:156-164

22. Kong F-Y, Li R-F, Yao L, Wang Z-X, Li H-Y, Lv W-X, Wang W (2019) Voltammetric simultaneous determination of catechol and hydroquinone using a glassy carbon electrode modified with a ternary hybrid material composed of reduced graphene oxide, magnetite nanoparticles and gold nanoparticles. Microchim Acta 186:177

23. Kang JH, Kim T, Choi J, Park J, Kim YS, Chang MS, Jung H, Park KT, Yang SJ, Park CR (2016) Hidden second oxidation step of Hummers method. Chem Mater 28:756-764

24. Stankovich S, Dikin DA, Dommett GHB, Kohlhaas KM, Zimney EJ, Stach EA, Piner RD, Nguyen ST, Ruoff RS (2006) Graphenebased composite materials. Nature 442:282-286

25. Eigler S, Enzelberger-Heim M, Grimm S, Hofmann P, Kroener W, Geworski A, Dotzer C, Röckert M, Xiao J, Papp C, Lytken O, Steinrück H-P, Müller P, Hirsch A (2013) Wet chemical synthesis of graphene. Adv Mater 25:3583-3587

26. Ghosh R, Nayak AK, Santra S, Pradhan D, Guha PK (2015) Enhanced ammonia sensing at room temperature with reduced graphene oxide/tin oxide hybrid films. RSC Adv 5:50165-50173

27. Wang X, Gu D, Li X, Lin S, Zhao S, Rumyantseva MN, Gaskov AM (2019) Reduced graphene oxide hybridized with $\mathrm{WS}_{2}$ nanoflakes based heterojunctions for selective ammonia sensors at room temperature. Sensors Actuators B Chem 282:290-299

28. Yoo SS, Kim SY, Kim KS, Hong S, Oh MJ, Nam MG, Kim W-J, Park J, Chung C-H, Choe W-S, Yoo PJ (2020) Controlling intersheet-distance in reduced graphene oxide electrodes for highly sensitive electrochemical impedimetric sensing of myoglobin. Sensors Actuators B Chem 305:127477

29. Wang Z, Sackmann A, Gao S, Weimar U, Lu G, Liu S, Zhang T, Barsan N (2019) Study on highly selective sensing behavior of ppb-level oxidizing gas sensors based on $\mathrm{Zn}_{2} \mathrm{SnO}_{4}$ nanoparticles immobilized on reduced graphene oxide under humidity conditions. Sensors Actuators B Chem 285:590-600

30. Yusoff N, Rameshkumar P, Mehmood MS, Pandikumar A, Lee HW, Huang NM (2017) Ternary nanohybrid of reduced graphene oxide-nafion@silver nanoparticles for boosting the sensor performance in non-enzymatic amperometric detection of hydrogen peroxide. Biosens Bioelectron 87:1020-1028

31. Pei S, Cheng H-M (2012) The reduction of graphene oxide. Carbon 50:3210-3228

32. Cai B, Wang S, Huang L, Ning Y, Zhang Z, Zhang G-J (2014) Ultrasensitive label-free detection of PNA-DNA hybridization by reduced graphene oxide field-effect transistor biosensor. ACS Nano 8:2632-2638

33. Chua CK, Pumera M (2014) Chemical reduction of graphene oxide: a synthetic chemistry viewpoint. Chem Soc Rev 43:291-312

34. Becerril HA, Mao J, Liu Z, Stoltenberg RM, Bao Z, Chen Y (2008) Evaluation of solution-processed reduced graphene oxide films as transparent conductors. ACS Nano 2:463-470 
35. Bai Z, Dong W, Ren Y, Zhang C, Chen Q (2018) Preparation of nano $\mathrm{Au}$ and Pt Alloy microspheres decorated with reduced graphene oxide for nonenzymatic hydrogen peroxide sensing. Langmuir 34:2235-2244

36. Chen D, Feng H, Li J (2012) Graphene oxide: preparation, functionalization, and electrochemical applications. Chem Rev 112:6027-6053

37. Zöpfl A, Lemberger M-M, König M, Ruhl G, Matysik F-M, Hirsch T (2014) Reduced graphene oxide and graphene composite materials for improved gas sensing at low temperature. Faraday Discuss 173:403-414

38. Xu X, Liu C, Sun Z, Cao T, Zhang Z, Wang E, Liu Z, Liu K (2018) Interfacial engineering in graphene bandgap. Chem Soc Rev 47:3059-3099

39. Yang Y, Hou H, Zou G, Shi W, Shuai H, Li J, Ji X (2018) Electrochemical exfoliation of graphene-like two-dimensional nanomaterials. Nanoscale 11:16-33

40. Ambrosi A, Pumera M (2018) Exfoliation of layered materials using electrochemistry. Chem Soc Rev 47:7213-7224

41. Zeng Z, Yin Z, Huang X, Li H, He Q, Lu G, Boey F, Zhang H (2011) Single-layer semiconducting nanosheets: high-yield preparation and device fabrication. Angew Chem Int Ed Eng 50: 11093-11097

42. Wang J, Manga KK, Bao Q, Loh KP (2011) High-yield synthesis of few-layer graphene flakes through electrochemical expansion of graphite in propylene carbonate electrolyte. J Am Chem Soc 133:8888-8891

43. Lin Z, Liu Y, Halim U, Ding M, Liu Y, Wang Y, Jia C, Chen P, Duan X, Wang C, Song F, Li M, Wan C, Huang Y, Duan X (2018) Solution-processable 2D semiconductors for highperformance large-area electronics. Nature 562:254-258

44. Parvez K, Wu Z-S, Li R, Liu X, Graf R, Feng X, Müllen K (2014) Exfoliation of graphite into graphene in aqueous solutions of inorganic salts. J Am Chem Soc 136:6083-6091

45. Ambrosi A, Pumera M (2016) Electrochemically exfoliated graphene and graphene oxide for energy storage and electrochemistry applications. Chem Eur J 22:153-159

46. Deng B, Liu Z, Peng H (2019) Toward mass production of CVD graphene films. Adv Mater 31:e1800996

47. Li X, Colombo L, Ruoff RS (2016) Synthesis of graphene films on copper foils by chemical vapor deposition. Adv Mater 28:62476252

48. Chen X, Zhang L, Chen S (2015) Large area CVD growth of graphene. Synth Met 210:95-108

49. Seah C-M, Chai S-P, Mohamed AR (2014) Mechanisms of graphene growth by chemical vapour deposition on transition metals. Carbon 70:1-21

50. Miseikis V, Convertino D, Mishra N, Gemmi M, Mashoff T, Heun S, Haghighian N, Bisio F, Canepa M, Piazza V, Coletti C (2015) Rapid CVD growth of millimetre-sized single crystal graphene using a cold-wall reactor. 2D Mater 2:14006

51. Lee E, Baek J, Park JS, Kim J, Yuk JM, Jeon S (2019) Effect of nucleation density on the crystallinity of graphene grown from mobile hot-wire-assisted CVD. 2D Mater 6:11001

52. Muñoz R, Gómez-Aleixandre C (2013) Review of CVD synthesis of graphene. Chem Vap Depos 19:297-322

53. Gao L, Ren W, Xu H, Jin L, Wang Z, Ma T, Ma L-P, Zhang Z, Fu Q, Peng L-M, Bao X, Cheng H-M (2012) Repeated growth and bubbling transfer of graphene with millimetre-size single-crystal grains using platinum. Nat Commun 3:699

54. Chen Y, Gong X-L, Gai J-G (2016) Progress and challenges in transfer of large-area graphene films. Adv Sci 3:1500343

55. Deng S, Berry V (2016) Wrinkled, rippled and crumpled graphene: an overview of formation mechanism, electronic properties, and applications. Mater Today 19:197-212
56. Hwang MT, Heiranian M, Kim Y, You S, Leem J, Taqieddin A, Faramarzi V, Jing Y, Park I, van der Zande AM, Nam S, Aluru NR, Bashir R (2020) Ultrasensitive detection of nucleic acids using deformed graphene channel field effect biosensors. Nat Commun 11:1543

57. Kodu M, Berholts A, Kahro T, Avarmaa T, Kasikov A, Niilisk A, Alles H, Jaaniso R (2016) Highly sensitive $\mathrm{NO}_{2}$ sensors by pulsed laser deposition on graphene. Appl Phys Lett 109:113108

58. Li J, Liu Z, Guo Q, Yang S, Xu A, Wang Z, Wang G, Wang Y, Chen D, Ding G (2019) Controllable growth of vertically oriented graphene for high sensitivity gas detection. J Mater Chem C 7: 5995-6003

59. Shen J, He Y, Wu J, Gao C, Keyshar K, Zhang X, Yang Y, Ye M, Vajtai R, Lou J, Ajayan PM (2015) Liquid phase exfoliation of two-dimensional materials by directly probing and matching surface tension components. Nano Lett 15:5449-5454

60. Paton KR, Varrla E, Backes C, Smith RJ, Khan U, O'Neill A, Boland C, Lotya M, Istrate OM, King P, Higgins T, Barwich S, May P, Puczkarski P, Ahmed I, Moebius M, Pettersson H, Long E, Coelho J, O'Brien SE, McGuire EK, Sanchez BM, Duesberg GS, McEvoy N, Pennycook TJ, Downing C, Crossley A, Nicolosi V, Coleman JN (2014) Scalable production of large quantities of defect-free few-layer graphene by shear exfoliation in liquids. Nat Mater 13:624-630

61. Ciesielski A, Samorì P (2014) Graphene via sonication assisted liquid-phase exfoliation. Chem Soc Rev 43:381-398

62. Backes C, Higgins TM, Kelly A, Boland C, Harvey A, Hanlon D, Coleman JN (2017) Guidelines for exfoliation, characterization and processing of layered materials produced by liquid exfoliation. Chem Mater 29:243-255

63. Hernandez Y, Nicolosi V, Lotya M, Blighe FM, Sun Z, De S, McGovern IT, Holland B, Byrne M, Gun'Ko YK, Boland JJ, Niraj P, Duesberg G, Krishnamurthy S, Goodhue R, Hutchison J, Scardaci V, Ferrari AC, Coleman JN (2008) High-yield production of graphene by liquid-phase exfoliation of graphite. Nat Nanotechnol 3:563-568

64. Tao H, Zhang Y, Gao Y, Sun Z, Yan C, Texter J (2017) Scalable exfoliation and dispersion of two-dimensional materials - an update. Phys Chem Chem Phys 19:921-960

65. Liu L, Shen Z, Yi M, Zhang X, Ma S (2014) A green, rapid and size-controlled production of high-quality graphene sheets by hydrodynamic forces. RSC Adv 4:36464-36470

66. Biccai S, Barwich S, Boland D, Harvey A, Hanlon D, McEvoy N, Coleman JN (2019) Exfoliation of 2D materials by high shear mixing. 2D Mater 6:15008

67. Coleman JN (2013) Liquid exfoliation of defect-free graphene. Acc Chem Res 46:14-22

68. Hu G, Kang J, Ng LWT, Zhu X, Howe RCT, Jones CG, Hersam MC, Hasan T (2018) Functional inks and printing of twodimensional materials. Chem Soc Rev 47:3265-3300

69. Kang J, Sangwan VK, Wood JD, Hersam MC (2017) Solutionbased processing of monodisperse two-dimensional nanomaterials. Acc Chem Res 50:943-951

70. Wei P, Shen J, Wu K, Yang N (2019) Defect-dependent electrochemistry of exfoliated graphene layers. Carbon 154:125-131

71. Wu C, Cheng Q, Wu K (2015) Electrochemical functionalization of N-methyl-2-pyrrolidone-exfoliated graphene nanosheets as highly sensitive analytical platform for phenols. Anal Chem 87: 3294-3299

72. Niu L, Coleman JN, Zhang H, Shin H, Chhowalla M, Zheng Z (2016) Production of two-dimensional nanomaterials via liquidbased direct exfoliation. Small 12:272-293

73. Lotya M, Hernandez Y, King PJ, Smith RJ, Nicolosi V, Karlsson LS, Blighe FM, De S, Wang Z, McGovern IT, Duesberg GS, Coleman JN (2009) Liquid phase production of graphene by 
exfoliation of graphite in surfactant/water solutions. J Am Chem Soc 131:3611-3620

74. Bosch-Navarro C, Laker ZPL, Rourke JP, Wilson NR (2015) Reproducible, stable and fast electrochemical activity from easy to make graphene on copper electrodes. Phys Chem Chem Phys 17:29628-29636

75. Georgakilas V, Otyepka M, Bourlinos AB, Chandra V, Kim N, Kemp KC, Hobza P, Zboril R, Kim KS (2012) Functionalization of graphene: covalent and non-covalent approaches, derivatives and applications. Chem Rev 112:6156-6214

76. Georgakilas V, Tiwari JN, Kemp KC, Perman JA, Bourlinos AB, Kim KS, Zboril R (2016) Noncovalent functionalization of graphene and graphene oxide for energy materials, biosensing, catalytic, and biomedical applications. Chem Rev 116:5464-5519

77. Shin DH, Kim W, Jun J, Lee JS, Kim JH, Jang J (2018) Highly selective FET-type glucose sensor based on shape-controlled palladium nanoflower-decorated graphene. Sensors Actuators B Chem 264:216-223

78. Loo AH, Ambrosi A, Bonanni A, Pumera M (2014) CVD graphene based immunosensor. RSC Adv 4:23952-23956

79. Cao S-H, Li L-H, Wei W-Y, Feng Y, Jiang W-L, Wang J-L, Zhang X-P, Cai S-H, Chen Z (2019) A label-free and ultrasensitive DNA impedimetric sensor with enzymatic and electrical dualamplification. Analyst 144:4175-4179

80. Wang Y, Sauriat-Dorizon H, Korri-Youssoufi H (2017) Direct electrochemical DNA biosensor based on reduced graphene oxide and metalloporphyrin nanocomposite. Sensors Actuators B Chem 251:40-48

81. Coros M, Pogăcean F, Măgerușan L, Roșu M-C, Porav AS, Socaci C, Bende A, Stefan-van Staden R-I, Pruneanu S (2018) Grapheneporphyrin composite synthesis through graphite exfoliation: the electrochemical sensing of catechol. Sensors Actuators B Chem 256:665-673

82. Campos R, Borme J, Guerreiro JR, Machado G, Cerqueira MF, Petrovykh DY, Alpuim P (2019) Attomolar label-free detection of DNA hybridization with electrolyte-gated graphene field-effect transistors. ACS Sens 4:286-293

83. Singh VK, Kumar S, Pandey SK, Srivastava S, Mishra M, Gupta G, Malhotra BD, Tiwari RS, Srivastava A (2018) Fabrication of sensitive bioelectrode based on atomically thin CVD grown graphene for cancer biomarker detection. Biosens Bioelectron 105:173-181

84. Luo Y, Kong F-Y, Li C, Shi J-J, Lv W-X, Wang W (2016) Onepot preparation of reduced graphene oxide-carbon nanotube decorated with Au nanoparticles based on protein for non-enzymatic electrochemical sensing of glucose. Sensors Actuators B Chem 234:625-632

85. Pogacean F, Coros M, Magerusan L, Rosu M-C, Socaci C, Gergely S, van Staden R-IS, Moldovan M, Sarosi C, Pruneanu S (2018) Sensitive detection of hydroquinone using exfoliated graphene-Au/glassy carbon modified electrode. Nanotechnology 29:95501

86. He C, Wang J, Gao N, He H, Zou K, Ma M, Zhou Y, Cai Z, Chang G, He Y (2019) A gold electrode modified with a gold-graphene oxide nanocomposite for non-enzymatic sensing of glucose at near-neutral $\mathrm{pH}$ values. Microchim Acta 186:722

87. Oh J, Lee JS, Jun J, Kim SG, Jang J (2017) Ultrasensitive and selective organic FET-type nonenzymatic dopamine sensor based on platinum nanoparticles-decorated reduced graphene oxide. ACS Appl Mater Interfaces 9:39526-39533

88. Eissa S, Jimenez GC, Mahvash F, Guermoune A, Tlili C, Szkopek T, Zourob M, Siaj M (2015) Functionalized CVD monolayer graphene for label-free impedimetric biosensing. Nano Res 8: 1698-1709

89. Ares P, Pisarra M, Segovia P, Díaz C, Martín F, Michel EG, Zamora F, Gómez-Navarro C, Gómez-Herrero J (2019) Tunable graphene electronics with local ultrahigh pressure. Adv Funct Mater 29:1806715

90. Kim MA, Qiu N, Li Z, Huang Q, Chai Z, Du S, Liu H (2020) Electric field effect on the reactivity of solid state materials: the case of single layer graphene. Adv Funct Mater 30:1909269

91. Liu Y, Huang Y, Duan X (2019) Van der Waals integration before and beyond two-dimensional materials. Nature 567:323-333

92. Azadmanjiri J, Srivastava VK, Kumar P, Sofer Z, Min J, Gong J (2020) Graphene-supported 2D transition metal dichalcogenide van der waals heterostructures. Appl Mater Today 19:100600

93. Sanati A, Jalali M, Raeissi K, Karimzadeh F, Kharaziha M, Mahshid SS, Mahshid S (2019) A review on recent advancements in electrochemical biosensing using carbonaceous nanomaterials. Microchim Acta 186:773

94. Xu J, Wang Y, Hu S (2017) Nanocomposites of graphene and graphene oxides: synthesis, molecular functionalization and application in electrochemical sensors and biosensors. A review. Microchim Acta 184:1-44

95. Fu W, Jiang L, van Geest EP, Lima LMC, Schneider GF (2017) Sensing at the surface of graphene field-effect transistors. Adv Mater 29:1603610

96. Bobrinetskiy II, Knezevic NZ (2018) Graphene-based biosensors for on-site detection of contaminants in food. Anal Methods 10: 5061-5070

97. Gan T, Hu S (2011) Electrochemical sensors based on graphene materials. Microchim Acta 175:1-19

98. Goldsmith BR, Locascio L, Gao Y, Lerner M, Walker A, Lerner J, Kyaw J, Shue A, Afsahi S, Pan D, Nokes J, Barron F (2019) Digital biosensing by foundry-fabricated graphene sensors. Sci Rep 9:434

99. Wang Z, Jia Y (2018) Graphene solution-gated field effect transistor DNA sensor fabricated by liquid exfoliation and double glutaraldehyde cross-linking. Carbon 130:758-767

100. Kwon SS, Shin JH, Choi J, Nam S, Park WI (2017) Defectmediated molecular interaction and charge transfer in graphene mesh-glucose sensors. ACS Appl Mater Interfaces 9:1421614221

101. Ang PK, Chen W, Wee ATS, Loh KP (2008) Solution-gated epitaxial graphene as $\mathrm{pH}$ sensor. J Am Chem Soc 130:14392-14393

102. Piccinini E, Bliem C, Reiner-Rozman C, Battaglini F, Azzaroni O, Knoll W (2017) Enzyme-polyelectrolyte multilayer assemblies on reduced graphene oxide field-effect transistors for biosensing applications. Biosens Bioelectron 92:661-667

103. Li Y, Zhu Y, Wang C, He M, Lin Q (2019) Selective detection of water pollutants using a differential aptamer-based graphene biosensor. Biosens Bioelectron 126:59-67

104. Kwon SS, Yi J, Lee WW, Shin JH, Kim SH, Cho SH, Nam S, Park WI (2016) Reversible and irreversible responses of defect engineered graphene-based electrolyte-gated $\mathrm{pH}$ sensors. ACS Appl Mater Interfaces 8:834-839

105. Li Y, Wang C, Zhu Y, Zhou X, Xiang Y, He M, Zeng S (2017) Fully integrated graphene electronic biosensor for label-free detection of lead (II) ion based on G-quadruplex structure-switching. Biosens Bioelectron 89:758-763

106. Xiong C, Zhang T, Wang D, Lin Y, Qu H, Chen W, Luo L, Wang Y, Zheng L, Fu L (2018) Highly sensitive solution-gated graphene transistor based sensor for continuous and real-time detection of free chlorine. Anal Chim Acta 1033:65-72

107. Sheldon RA, van Pelt S (2013) Enzyme immobilisation in biocatalysis: why, what and how. Chem Soc Rev 42:6223-6235

108. Niyogi S, Bekyarova E, Itkis ME, Zhang H, Shepperd K, Hicks J, Sprinkle M, Berger C, Lau CN, deHeer WA, Conrad EH, Haddon RC (2010) Spectroscopy of covalently functionalized graphene. Nano Lett 10:4061-4066 
109. Reiner-Rozman C, Larisika M, Nowak C, Knoll W (2015) Graphene-based liquid-gated field effect transistor for biosensing: Theory and experiments. Biosens Bioelectron 70:21-27

110. Seo G, Lee G, Kim MJ, Baek S-H, Choi M, Ku KB, Lee C-S, Jun S, Park D, Kim HG, Kim S-J, Lee J-O, Kim BT, Park EC, Kim SI (2020) Rapid detection of COVID-19 causative virus (SARS$\mathrm{CoV}-2$ ) in human nasopharyngeal swab specimens using fieldeffect transistor-based biosensor. ACS Nano. https://doi.org/10. 1021/acsnano.0c02823

111. Mackin C, Schroeder V, Zurutuza A, Su C, Kong J, Swager TM, Palacios T (2018) Chemiresistive graphene sensors for ammonia detection. ACS Appl Mater Interfaces 10:16169-16176

112. Luengas A, Barona A, Hort C, Gallastegui G, Platel V, Elias A (2015) A review of indoor air treatment technologies. Rev Environ Sci Biotechnol 14:499-522

113. Di Rosa AR, Leone F, Cheli F, Chiofalo V (2017) Fusion of electronic nose, electronic tongue and computer vision for animal source food authentication and quality assessment - A review. J Food Eng 210:62-75

114. Li Y, Wang B, Yu Z, Zhou X, Di Kang WY, Chen Z, He C, Zhou $X$ (2017) The effects of central metals on ammonia sensing of metallophthalocyanines covalently bonded to graphene oxide hybrids. RSC Adv 7:34215-34225

115. Karaduman I, Er E, Çelikkan H, Erk N, Acar S (2017) Roomtemperature ammonia gas sensor based on reduced graphene oxide nanocomposites decorated by $\mathrm{Ag}$, Au and Pt nanoparticles. J Alloys Compd 722:569-578

116. Chen Y, Zhang W, Wu Q (2017) A highly sensitive roomtemperature sensing material for $\mathrm{NH}_{3}: \mathrm{SnO}_{2}$-nanorods coupled by rGO. Sensors Actuators B Chem 242:1216-1226

117. Song H, Li X, Cui P, Guo S, Liu W, Wang X (2017) Morphology optimization of CVD graphene decorated with Ag nanoparticles as ammonia sensor. Sensors Actuators B Chem 244:124-130

118. Kampara RK, Rai PK, Jeyaprakash BG (2018) Highly sensitive graphene oxide functionalized $\mathrm{ZnO}$ nanowires for ammonia vapour detection at ambient temperature. Sensors Actuators B Chem 255:1064-1071

119. Andre RS, Mercante LA, Facure MHM, Mattoso LHC, Correa DS (2019) Enhanced and selective ammonia detection using $\operatorname{In}_{2} \mathrm{O}_{3} /$ reduced graphene oxide hybrid nanofibers. Appl Surf Sci 473: 133-140

120. Qin J, Gao J, Shi X, Chang J, Dong Y, Zheng S, Wang X, Feng L, Wu Z-S (2020) Hierarchical ordered dual-mesoporous polypyrrole/graphene nanosheets as bi-functional active materials for high-performance planar integrated system of microsupercapacitor and gas sensor. Adv Funct Mater 30:1909756

121. Lee SH, Eom W, Shin H, Ambade RB, Bang JH, Kim HW, Han $\mathrm{TH}$ (2020) Room-temperature, highly durable $\mathrm{Ti}_{3} \mathrm{C}_{2} \mathrm{~T}_{\mathrm{x}}$ MXene/ graphene hybrid fibers for $\mathrm{NH}_{3}$ gas sensing. ACS Appl Mater Interfaces 12:10434-10442

122. Kim YH, Park JS, Choi Y-R, Park SY, Lee SY, Sohn W, Shim YS, Lee J-H, Park CR, Choi YS, Hong BH, Lee JH, Lee WH, Lee D, Jang HW (2017) Chemically fluorinated graphene oxide for room temperature ammonia detection at ppb levels. J Mater Chem A 5:19116-19125

123. Heydari-Bafrooei E, Askari S (2017) Ultrasensitive aptasensing of lysozyme by exploiting the synergistic effect of gold nanoparticlemodified reduced graphene oxide and MWCNTs in a chitosan matrix. Microchim Acta 184:3405-3413

124. Heydari-Bafrooei E, Shamszadeh NS (2017) Electrochemical bioassay development for ultrasensitive aptasensing of prostate specific antigen. Biosens Bioelectron 91:284-292

125. Rostamabadi PF, Heydari-Bafrooei E (2019) Impedimetric aptasensing of the breast cancer biomarker HER2 using a glassy carbon electrode modified with gold nanoparticles in a composite consisting of electrochemically reduced graphene oxide and single-walled carbon nanotubes. Microchim Acta 186:495

126. Gong Q, Han H, Yang H, Zhang M, Sun X, Liang Y, Liu Z, Zhang W, Qiao J (2019) Sensitive electrochemical DNA sensor for the detection of HIV based on a polyaniline/graphene nanocomposite. J Mater 5:313-319

127. Shahrokhian S, Salimian R (2018) Ultrasensitive detection of cancer biomarkers using conducting polymer/electrochemically reduced graphene oxide-based biosensor: application toward BRCA1 sensing. Sensors Actuators B Chem 266:160-169

128. Imran H, Manikandan PN, Dharuman V (2018) Graphene oxide supported liposomes for efficient label free electrochemical DNA biosensing. Sensors Actuators B Chem 260:841-851

129. Shamsipur M, Samandari L, Taherpour AA, Pashabadi A (2019) Sub-femtomolar detection of HIV-1 gene using DNA immobilized on composite platform reinforced by a conductive polymer sandwiched between two nanostructured layers: A solid signal-amplification strategy. Anal Chim Acta 1055:7-16

130. Jayakumar K, Camarada MB, Dharuman V, Ju H, Dey RS, Wen Y (2018) One-step coelectrodeposition-assisted layer-by-layer assembly of gold nanoparticles and reduced graphene oxide and its self-healing three-dimensional nanohybrid for an ultrasensitive DNA sensor. Nanoscale 10:1196-1206

131. Nagar B, Balsells M, La Escosura-Muñiz A d, Gomez-Romero P, Merkoçi A (2019) Fully printed one-step biosensing device using graphene/AuNPs composite. Biosens Bioelectron 129:238-244

132. Low SS, Loh H-S, Boey JS, Khiew PS, Chiu WS, Tan MTT (2017) Sensitivity enhancement of graphene/zinc oxide nanocomposite-based electrochemical impedance genosensor for single stranded RNA detection. Biosens Bioelectron 94:365-373

133. Xu S (2017) Electrochemical DNA biosensor based on graphene oxide- chitosan hybrid nanocomposites for detection of Escherichia Coli O157:H7. Int J Electrochem Sci:3443-3458

134. Jaiswal N, Pandey CM, Solanki S, Tiwari I, Malhotra BD (2019) An impedimetric biosensor based on electrophoretically assembled $\mathrm{ZnO}$ nanorods and carboxylated graphene nanoflakes on an indium tin oxide electrode for detection of the DNA of Escherichia coli O157:H7. Microchim Acta 187:1

135. Zhang K, Zhang N, Zhang L, Wang H, Shi H, Liu Q (2018) Labelfree impedimetric sensing platform for microRNA-21 based on $\mathrm{ZrO}_{2}$-reduced graphene oxide nanohybrids coupled with catalytic hairpin assembly amplification. RSC Adv 8:16146-16151

136. Gong Q, Wang Y, Yang H (2017) A sensitive impedimetric DNA biosensor for the determination of the HIV gene based on graphene-Nafion composite film. Biosens Bioelectron 89:565569

137. Benvidi A, Saucedo NM, Ramnani P, Villarreal C, Mulchandani A, Tezerjani MD, Jahanbani S (2018) Electro-oxidized monolayer CVD graphene film transducer for ultrasensitive impedimetric DNA biosensor. Electroanalysis 30:1791-1800

138. Mohanraj J, Durgalakshmi D, Rakkesh RA, Balakumar S, Rajendran S, Karimi-Maleh H (2020) Facile synthesis of paper based graphene electrodes for point of care devices: a double stranded DNA (dsDNA) biosensor. J Colloid Interface Sci 566: $463-472$

139. Xu D, Zhu C, Meng X, Chen Z, Li Y, Zhang D, Zhu S (2018) Design and fabrication of $\mathrm{Ag}-\mathrm{CuO}$ nanoparticles on reduced graphene oxide for nonenzymatic detection of glucose. Sensors Actuators B Chem 265:435-442

140. Liu J, Yang C, Shang Y, Zhang P, Liu J, Zheng J (2018) Preparation of a nanocomposite material consisting of cuprous oxide, polyaniline and reduced graphene oxide, and its application to the electrochemical determination of hydrogen peroxide. Microchim Acta 185:172 
141. Bosch-Navarro C, Rourke JP, Wilson NR (2016) Controlled electrochemical and electroless deposition of noble metal nanoparticles on graphene. RSC Adv 6:73790-73796

142. Xuan X, Yoon HS, Park JY (2018) A wearable electrochemical glucose sensor based on simple and low-cost fabrication supported micro-patterned reduced graphene oxide nanocomposite electrode on flexible substrate. Biosens Bioelectron 109:75-82

143. Wang B, Wu Y, Chen Y, Weng B, Li C (2017) Flexible paper sensor fabricated via in situ growth of $\mathrm{Cu}$ nanoflower on $\mathrm{RGO}$ sheets towards amperometrically non-enzymatic detection of glucose. Sensors Actuators B Chem 238:802-808

144. Lee C-S, Yu SH, Kim TH (2017) One-step electrochemical fabrication of reduced graphene oxide/gold nanoparticles nanocomposite-modified electrode for simultaneous detection of dopamine, ascorbic acid, and uric acid. Nanomaterials 8

145. Lin S, Feng W, Miao X, Zhang X, Chen S, Chen Y, Wang W, Zhang Y (2018) A flexible and highly sensitive nonenzymatic glucose sensor based on DVD-laser scribed graphene substrate. Biosens Bioelectron 110:89-96

146. Shabnam L, Faisal SN, Roy AK, Haque E, Minett AI, Gomes VG (2017) Doped graphene/Cu nanocomposite: a high sensitivity non-enzymatic glucose sensor for food. Food Chem 221:751-759

147. Zhang Y, Lei W, Wu Q, Xia X, Hao Q (2017) Amperometric nonenzymatic determination of glucose via a glassy carbon electrode modified with nickel hydroxide and $\mathrm{N}$-doped reduced graphene oxide. Microchim Acta 184:3103-3111

148. Zheng W, Hu L, Lee LYS, Wong K-Y (2016) Copper nanoparticles/polyaniline/graphene composite as a highly sensitive electrochemical glucose sensor. J Electroanal Chem 781:155-160

149. Geng D, Bo X, Guo L (2017) Ni-doped molybdenum disulfide nanoparticles anchored on reduced graphene oxide as novel electroactive material for a non-enzymatic glucose sensor. Sensors Actuators B Chem 244:131-141

150. Thanh TD, Balamurugan J, Hwang JY, Kim NH, Lee JH (2016) In situ synthesis of graphene-encapsulated gold nanoparticle hybrid electrodes for non-enzymatic glucose sensing. Carbon 98:90-98

151. Wei S, Hao Y, Ying Z, Xu C, Wei Q, Xue S, Cheng H-M, Ren W, Ma L-P, Zeng Y (2020) Transfer-free CVD graphene for highly sensitive glucose sensors. J Mater Sci Nanotechnol 37:71-76

152. Aparicio-Martínez E, Ibarra A, Estrada-Moreno IA, Osuna V, Dominguez RB (2019) Flexible electrochemical sensor based on laser scribed graphene/Ag nanoparticles for non-enzymatic hydrogen peroxide detection. Sensors Actuators B Chem 301:127101

153. Lu Z, Wu L, Zhang J, Dai W, Mo G, Ye J (2019) Bifunctional and highly sensitive electrochemical non-enzymatic glucose and hydrogen peroxide biosensor based on $\mathrm{NiCo}_{2} \mathrm{O}_{4}$ nanoflowers decorated 3D nitrogen doped holey graphene hydrogel. Mater Sci Eng C 102:708-717

154. Amanulla B, Palanisamy S, Chen S-M, Velusamy V, Chiu T-W, Chen T-W, Ramaraj SK (2017) A non-enzymatic amperometric hydrogen peroxide sensor based on iron nanoparticles decorated reduced graphene oxide nanocomposite. J Colloid Interface Sci 487:370-377

155. Zhang Y, Duan Y, Shao Z, Chen C, Yang M, Lu G, Xu W, Liao X (2019) Amperometric hydrogen peroxide sensor using a glassy carbon electrode modified with a nanocomposite prepared from ferumoxytol and reduced graphene oxide decorated with platinum nanoparticles. Microchim Acta 186:386

156. Yuan Y, Zheng Y, Liu J, Wang H, Hou S (2017) Non-enzymatic amperometric hydrogen peroxide sensor using a glassy carbon electrode modified with gold nanoparticles deposited on CVDgrown graphene. Microchim Acta 184:4723-4729

157. Wang J, Sun H-b, Pan H-y, Ding Y-y, Wan J-g, Wang G-h, Han M (2016) Detection of hydrogen peroxide at a palladium nanoparticle-bilayer graphene hybrid-modified electrode. Sensors Actuators B Chem 230:690-696

158. Dau TNN, Vu VH, Cao TT, van Nguyen C, Ly CT, Tran DL, Pham TTN, Loc NT, Piro B, Vu TT (2019) In-situ electrochemically deposited $\mathrm{Fe}_{3} \mathrm{O}_{4}$ nanoparticles onto graphene nanosheets as amperometric amplifier for electrochemical biosensing applications. Sensors Actuators B Chem 283:52-60

159. Hsu S-Y, Lee C-L (2017) Sonoelectrochemical exfoliation of highly oriented pyrolytic graphite for preparing defective fewlayered graphene with promising activity for non-enzymatic $\mathrm{H}_{2} \mathrm{O}_{2}$ sensors. Microchim Acta 184:2489-2496

160. Velický M, Toth PS (2017) From two-dimensional materials to their heterostructures: an electrochemist's perspective. Appl Mater Today 8:68-103

161. Kauling AP, Seefeldt AT, Pisoni DP, Pradeep RC, Bentini R, Oliveira RV, Novoselov KS, Castro Neto AH (2018) The worldwide graphene flake production. Adv Mater 44:1803784

162. Batra G, Santhanam N, Surana K (2018) Graphene: The next Scurve for semiconductors? https://www.mckinsey.com/industries/ semiconductors/our-insights/graphene-the-next-s-curve-forsemiconductors. Accessed 18 May 2020

Publisher's note Springer Nature remains neutral with regard to jurisdictional claims in published maps and institutional affiliations. 